\title{
Development of mass and heat transfer coupled model of hollow fiber membrane for salt recovery from brine via osmotic membrane distillation
}

\author{
Sher Ahmad ${ }^{1}$, Gabriela Vollet Marson ${ }^{2}$, Waheed Ur Rehman ${ }^{3}$, Mohammad Younas ${ }^{1 *}$, Sarah Farrukh ${ }^{4}$ and
} Mashallah Rezakazemi ${ }^{*}$ (i)

\begin{abstract}
Background: In this research work, a coupled heat and mass transfer model was developed for salt recovery from concentrated brine water through an osmotic membrane distillation (OMD) process in a hollow fiber membrane contactor (HFMC). The model was built based on the resistance-in-series concept for water transport across the hydrophobic membrane. The model was adopted to incorporate the effects of polarization layers such as temperature and concentration polarization, as well as viscosity changes during concentration.

Results: The modeling equations were numerically simulated in $M A T L A B^{\circledR}$ and were successfully validated with experimental data from literature with a deviation within the range of $1-5 \%$. The model was then applied to study the effects of key process parameters like feed concentrations, osmotic solution concentration, feed, and osmotic solution flow rates and feed temperature on the overall heat and mass transfer coefficient as well as on water transport flux to improve the process efficiency. The mass balance modeling was applied to calculate the membrane area based on the simulated mass transfer coefficient. Finally, a scale-up for the MD process for salt recovery on an industrial scale was proposed.

Conclusions: This study highlights the effect of key parameters for salt recovery from wastewater using the membrane distillation process. Further, the applicability of the OMD process for salt recovery on large scale was investigated. Sensitivity analysis was performed to identify the key parameters. From the results of this study, it is concluded that the OMD process can be promising in salt recovery from wastewater.
\end{abstract}

Keywords: Hollow fiber membrane contactors, Osmotic membrane distillation, Salt recovery, Membrane crystallization, Heat and mass transfer modeling

*Correspondence: m.younas@uetpeshawar.edu.pk; mashalah. rezakazemi@gmail.com

${ }^{1}$ Department of Chemical Engineering, University of Engineering and Technology, Peshawar, Pakistan

${ }^{5}$ Faculty of Chemical and Materials Engineering, Shahrood University of Technology, Shahrood, Iran

Full list of author information is available at the end of the article

\section{Introduction}

Industrial wastewater effluents contain a large variety of useful chemical compounds. For example, effluents from the textile, metal, and petrochemical industries typically contain inorganic salts such as carbonates, sulfates, and nitrates. The recovery of these chemicals from wastewaters has many advantages. Firstly, they can be reused, decreasing the stress generated by the intensive extraction of natural resources. The clean water obtained can 
then be recycled back to perform industrial operations. Moreover, a continuous increase in salt concentration in wastewaters can cause environmental issues such as eutrophication or increased soil alkalinity, hence affecting cultivation land [1].

The study on the efficient recovery of inorganic salts from wastewater effluents is considered as a focusing area during the past decade. Different conventional techniques have already been implemented for this purpose, such as electrolysis, reverse osmosis, nanofiltration, ion exchange membrane processes, and evaporation [2-4]. However, most of the mentioned treatment techniques are expensive and involve complex processes that lead to solids in sludge form, which can be difficult to reutilize.

For salt recovery, crystallization is commonly used because it provides a very high-quality product with a high recovery rate. In the literature, several crystallization techniques have already been implemented for salt recovery from wastewater $[5,6]$. Among these, osmotic membrane distillation (OMD) is a promising technique because of the following advantages: (1) it can yield highly concentrated streams; (2) it can be operated at room temperature; and (3) a well-controlled supersaturation takes place [6-9]. Hollow fiber membrane contactors (HFMC) are commonly used to carry out OMD operations. HFMCs are the preferred choice over flat sheet membranes in OMD operation because they present high specific areas per unit volume, easy scale-up, and low manufacturing costs. HFMCs allow a non-dispersive contact between two phases due to the hydrophobic nature of the membrane without intimate mixing. The membrane used is hydrophobic to avoid any membrane wetting due to the presence of aqueous streams in boundary layers. During this process, water evaporates at the pore entry of the membrane from the feed side and is transported through its pores either by Knudsen or molecular diffusion and then condenses at the permeate side. The transport gradient between the two sides occurs due to the difference in chemical potential caused by water activity, pressure, or temperature gradients [1012]. Because the transfer of water occurs from the feed to the permeate side, the feed stream is concentrated. In the OMD process, crystallization occurs when the feed solution reaches supersaturation. The hydrophobic membrane surface allows heterogeneous nucleation and crystals are continuously driven away by the flow of the feed solution. Crystals can further grow when coupled to a crystallizer $[9,13,14]$.

Sodium carbonate $\left(\mathrm{Na}_{2} \mathrm{CO}_{3}\right)$ is commonly found in wastewater effluents coming from the sodium hydroxide-based $\mathrm{CO}_{2}$ capture process, which is an essential step to control $\mathrm{CO}_{2}$ emission [15]. The recovery of $\mathrm{Na}_{2} \mathrm{CO}_{3}$ is necessary so that the process is economically viable; therefore, evaporation and crystallization are usually applied in the chemical industry to recover solid $\mathrm{Na}_{2} \mathrm{CO}_{3}$ from wastewater [16]. Recently, membrane contactors appear as an alternative technique that can replace both conventional evaporation and crystallization operations because of their adaptability and low energy consumption [17]. The current research work focuses on the concentration of $\mathrm{Na}_{2} \mathrm{CO}_{3}$ solution till the saturation point, using OMD through a modeling and simulation approach.

Modeling and simulation are relatively cheaper, robust, and fast techniques as compared to the experimental methods, and if the model parameters are carefully estimated, the validated model can be used to replicate the experimental data and predict the scaling up of the process. Mass and heat transfer modeling of HFMCs is inevitable to study the concentration and flux profiles, to investigate the solute transport, to categorize the controlling resistance, for the optimization of the process operating parameters, and to scale up the process [13]. Scale-up of HFMC has not been widely studied for OMD in salt recovery during crystallization. More theoretical and simulation investigation is required to encourage the entrepreneurs to utilize HFMCs for the selected application at a large scale.

Different approaches are used to model the OMD process, however, the resistance-in-series (RIS) model approach is a widely applied and acceptable technique to predict water transport flux through the membrane [1821]. Most of the models used in literature based on the RIS model have not considered temperature/concentration polarization effects. Similarly, the effect of physical properties was considered constant during the concentration process. Ahmad et al. [13] studied the RIS model for osmotic membrane evaporation of fruit juices and found that physical properties like viscosity and density variations during the process had a significant effect on water flux. Ni et al. [22] studied the effect of temperature polarization in direct contact membrane distillation for $\mathrm{NaCl}$ concentration and observed that temperature polarization was enhanced with the increase of feed temperature and the decrease of feed and permeate velocity. Similarly, Lou et al. [23] investigated coupled temperature and concentration polarization in the membrane distillation treatment of brines with the help of the CFD heat and mass transfer model and observed the effect of coupled temperature and concentration polarization. Salmon et al. [24] experimentally applied the concept of OMD for the crystallization of inorganic salts using two HFMC in series. In another similar study, Salmon et al. [25] described the experimental and theoretical analysis of mass and heat transport of inorganic species during the OMD process. 
In the current research work, an RIS model coupling heat and mass transfer resistances was adapted to model HFMC for the recovery of inorganic salts from the brine solution via OMD operation. The model incorporates the effect of concentration polarization in the feed side as well as the osmotic solution side. An aqueous stream of $\mathrm{Na}_{2} \mathrm{CO}_{3}$ was taken as an inorganic salt. The model was successfully validated with experimental data under the same operating and module geometrical conditions from the literature [25]. The effects of temperature/concentration polarization of water flux were studied through the simulation of the developed model. Finally, the feasibility of large-scale OMD operation for recovery of $\mathrm{Na}_{2} \mathrm{CO}_{3}$ was studied by estimating the required membrane area for industrial conditions which provides an insight into the mass and heat transport phenomena and their implications in scale-up OMD-based HFMCs.

\section{Studied system}

The once-through HFMC-based OMD experimental setup studied in the current work for the salt recovery is shown in Fig. 1 [13]. For the crystallization of $\mathrm{Na}_{2} \mathrm{CO}_{3}$, a commercially available HFMC was used (specifications are provided in Table 1). Two peristaltic pumps circulated the feed stream (aqueous solution of $\mathrm{Na}_{2} \mathrm{CO}_{3}$ ) and the osmotic stream (aqueous solution of $\mathrm{NaCl}$ ) from their respective reservoirs to the HFMC module in a counter-current mode. The feed stream was circulated inside the lumen side of the membrane while the osmotic stream flowed in the shell side. The initial concentration of $\mathrm{Na}_{2} \mathrm{CO}_{3}$ in the feed stream was varied from 0 to $200 \mathrm{~g}$ $\mathrm{L}^{-1}$, while the concentration of the osmotic solution varied from 0 to $300 \mathrm{~g} \mathrm{~L}^{-1}$. The feed and osmotic flow rates were maintained between $0.90-30$ and 3-84 $\mathrm{L} \mathrm{h}^{-1}$, respectively. The temperature of the osmotic solution was kept constant at $293 \pm 1 \mathrm{~K}$ while the feed stream temperature was varied between 293 and $313 \mathrm{~K}$. However, all the
Table 1 Characteristics of HFMC [25]

\begin{tabular}{ll}
\hline Parameters & Data \\
\hline Membrane material & Polypropylene \\
Fiber ID/OD $(\mu \mathrm{m})$ & $240 / 300$ \\
Membrane thickness $(\mu \mathrm{m})$ & 30 \\
Membrane porosity $(\%)$ & 40 \\
Effective fiber length $(\mathrm{m})$ & 0.16 \\
Number of fibers $(-)$ & 10,200 \\
Effective membrane surface area $\left(\mathrm{m}^{2}\right)$ & 1.4 \\
Specific surface area of the membrane module $\left(\mathrm{m}^{2} \mathrm{~m}^{-3}\right)$ & 2000 \\
Effective pore size $(\mu \mathrm{m})$ & 0.04 \\
\hline
\end{tabular}

conditions were kept constant during a single course of the experiment.

\section{Theory}

The RIS model considered three major resistances to heat and mass transfer for water transport, i.e., feed side (fiber) boundary layer resistance $\left(k_{\beta} h_{f}\right)$, resistance within the membrane pores $\left(k_{m}, h_{m}\right)$ and osmotic solution side (shell) boundary layer resistance $\left(k_{o s}, h_{o s}\right)$. A simplified schematic of the HFMC module and all the transport resistances are shown in Fig. 2.

The model developed for the OMD process was based on the following assumptions $[10,26,27]$ :

i. The feed and osmotic streams were recirculated in recycled mode.

ii. Steady-state conditions for mass/heat transport in HFMC are taken.

iii. Water vapor transport across the membrane was based on the RIS for mass and heat transfer.

iv. The RIS model was applied to the identical concentric "flow-cell" concept.

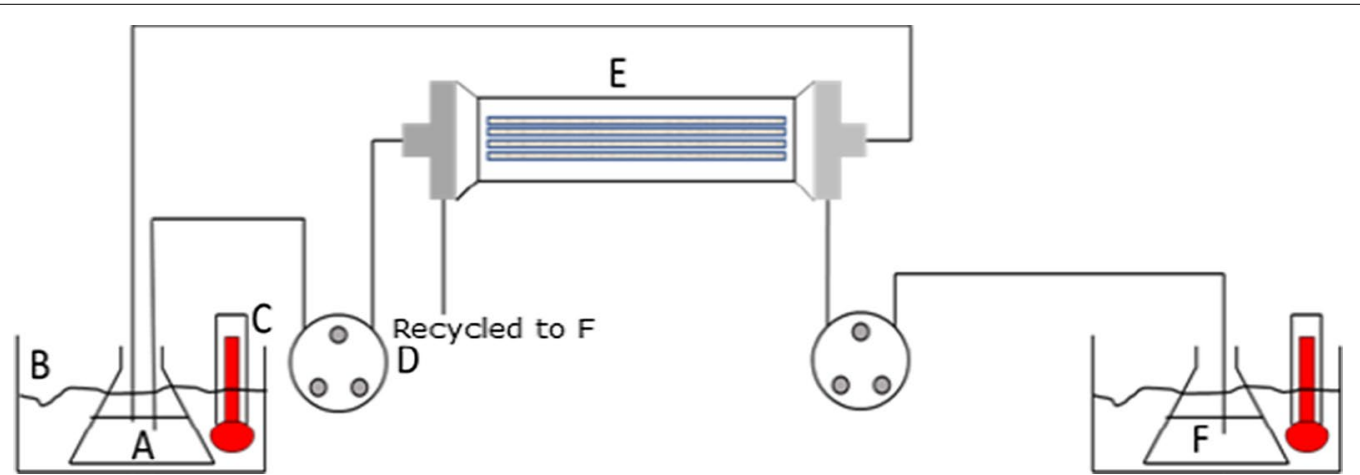

Fig. 1 OMD crystallization setup adopted from Salmón et al. [25]. A: feed tank, B: water bath, C: thermometer, D: peristaltic pump, E: hollow fiber membrane module, F: osmotic solution tank 


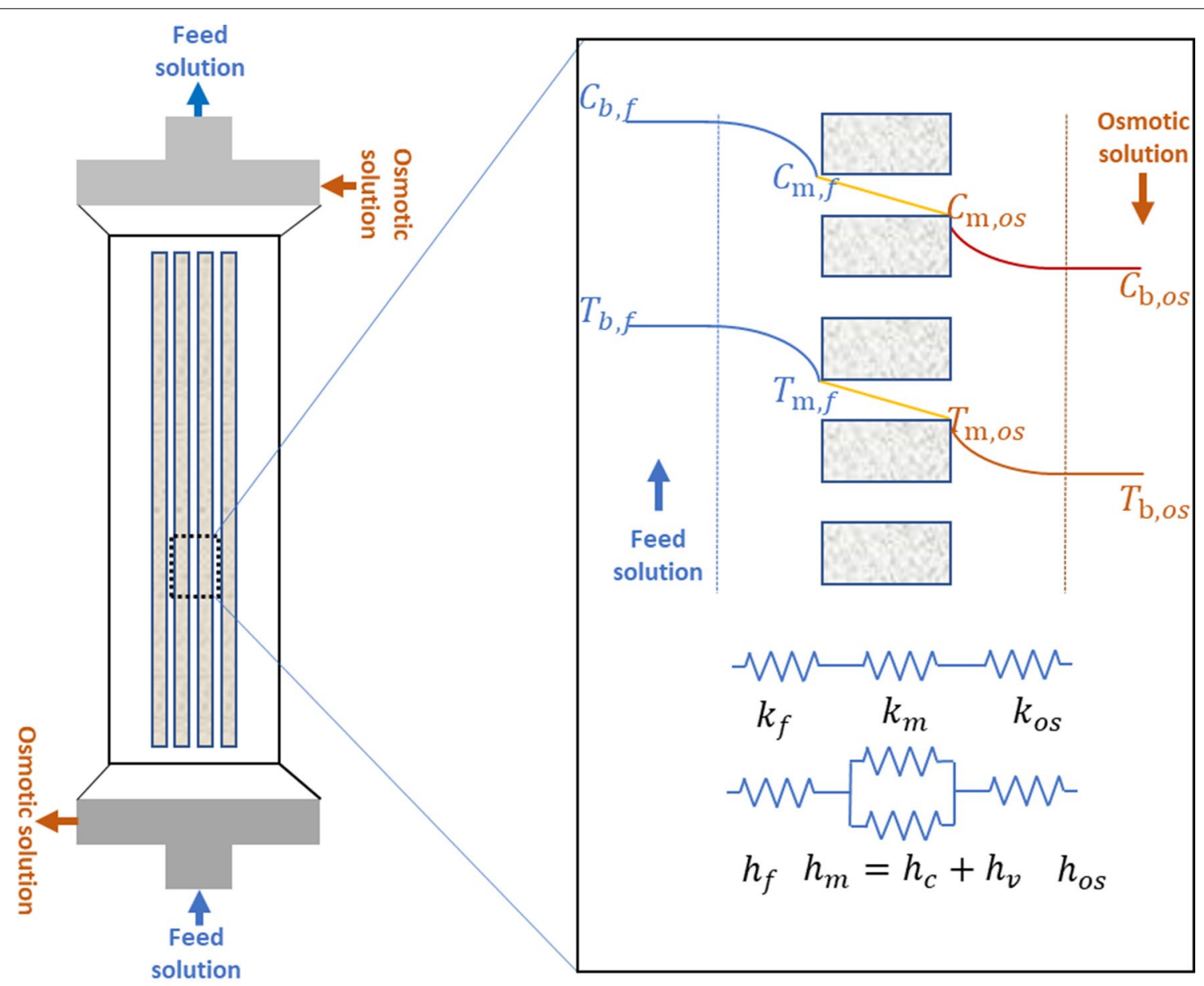

(a)

(b)

Fig. 2 a Hollow fiber membrane module operating in counter-current mode: fibers (feed solution), shell (osmotic solution); b resistance in the series model for heat and mass transfer

v. The concentration profile in all of the fibers (flowcells) is the same.

vi. Pore size and wetting characteristics are uniform throughout the membrane and fibers (flow-cells).

vii. The membrane is entirely hydrophobic and membrane wetting is negligible.

viii. Mass transport within the membrane occurs only in vapor form due to the hydrophobic nature of the membrane.

ix. Dispersion-free transfer of species takes place through a combined phenomenon of convection and diffusion.

x. Uniform mixing occurs within the feed as well as osmotic solution reservoirs.

xi. The concentration of the osmotic solution remains constant throughout the experiment, and hence the dilution effect is neglected. xii. The initial temperature of feed and osmotic streams was kept constant during the experiment.

In the RIS model, the mass and heat transport of water vapors can be expressed by Eqs. (1) and (2), respectively $[13,28]$ :

$$
\begin{aligned}
& J_{w}=K_{o v}\left(P_{f}^{*} a_{f}-P_{o s}^{*} a_{o s}\right), \\
& q=U \Delta T_{b},
\end{aligned}
$$

where $J_{w}$ is the water vapor flux through the membrane $\left(\mathrm{m}^{3} \mathrm{~m}^{-2} \mathrm{~s}^{-1}\right), P_{f}^{*}$ and $P_{\mathrm{os}}^{*}$ is the vapor pressure of the salt solutions in feed and osmotic solution $(\mathrm{Pa})$, respectively. $a_{f}$ and $a_{o s}$ is the activity of feed and osmotic solutions, respectively. $K_{o v}$ is the overall mass transfer coefficient $\left(\mathrm{m} \mathrm{s}^{-1} \mathrm{~Pa}^{-1}\right)$, calculated by the RIS integrated approach 
(Eq. (15)). Similarly, $q$ is the total heat transfer flux (W $\mathrm{m}^{-2}$ ); $U$ is the overall heat transfer coefficient (W $\mathrm{m}^{-2} \mathrm{~K}^{-1}$ ) and $\Delta T_{b}$ is the temperature difference between both sides of the membrane (K).

All physical properties such as density, viscosity, thermodynamic activities, and vapor pressures of the solutions are temperature and concentration-dependent and their variations during the concentration process influence the mass transfer coefficients and ultimately, the water flux through the membrane. Therefore, these properties were considered as variables in the model and calculated from the correlations, via Eqs. (30-33).

\section{Mass transfer coefficients}

\section{Feed side mass transfer coefficient}

The feed solution is passed through the lumen side of the HFMC module because the shell side is more prone to clogging at high concentrations $[11,18]$. Mass transfer coefficient at the feed side $\left(k_{f}\right)$, as described by Eq. (4), was calculated from Sherwood correlation considering the single fiber of the HFMC module [12, 25]:

$$
\begin{aligned}
& \text { Sh }=0.66 R e^{0.5} S c^{0.33}\left(\frac{d_{i}}{l}\right)^{0.33}, \\
& k_{f}=\frac{S h D_{f}}{d_{i}}, \\
& \operatorname{Re}=\frac{\rho_{f} v_{f} d_{i}}{\mu_{f}}, \\
& \text { Sc }=\frac{\mu_{f}}{\rho_{f} D_{f}},
\end{aligned}
$$

where Sh, Re, and Sc denote the Sherwood, Reynolds, and Schmidt numbers (dimensionless), respectively; $d i$ (m) stands for the inside diameter of lumen (m), $\rho_{f}$ for the density $\left(\mathrm{kg} \mathrm{m}^{-3}\right), \mu_{f}$ for the viscosity (Pa s) of the feed solution. Likewise, $v_{\mathrm{f}}$ and $D_{\mathrm{f}}$ denote the velocity $\left(\mathrm{m} \mathrm{s}^{-1}\right)$ of the feed through the fibers, and diffusivity $\left(\mathrm{m}^{2} \mathrm{~s}^{-1}\right)$ of $\mathrm{Na}_{2} \mathrm{CO}_{3}$ in water, respectively.

\section{Osmotic solution side mass transfer coefficient}

The osmotic solution was passed through the shell side of the HFMC module. The mass transfer coefficient at the shell side $\left(k_{o s}\right)$ was calculated from Eq. (7), an application of the Sherwood correlation [14, 19] (Eq. (8)):

$$
k_{o s}=\frac{\operatorname{Sh} D_{o s}}{d_{h}},
$$

$$
\begin{aligned}
& \mathrm{Sh}=5.8 \operatorname{Re}^{0.6} \mathrm{Sc}^{0.33}\left(\frac{d_{h}(1-\phi)}{l}\right), \\
& \operatorname{Re}=\frac{\rho_{o s} v_{\mathrm{os}} d_{h}}{\mu_{\mathrm{os}}}, \\
& \mathrm{Sc}=\frac{\mu_{o s}}{\rho_{o s} D_{\mathrm{os}}} .
\end{aligned}
$$

Here $D_{i}$ is the diffusion coefficient of salt $(\mathrm{NaCl})$ in the osmotic solutions $\left(\mathrm{m}^{2} \mathrm{~s}^{-1}\right), d_{h}$ is the hydraulic diameter $(\mathrm{m}) ; l$ is the length $(\mathrm{m})$ and $\phi$ is the packing density.

The diffusion coefficient $D_{i}\left(\mathrm{~m}^{2} \mathrm{~s}^{-1}\right)$ of species in water was calculated using the Wilke-Chang [29] (Eq. (11)).

$$
D_{i}=\frac{7.4 \times 10^{-8}\left(\phi_{B} M_{B}\right)^{\frac{1}{2}} T}{\mu_{B} V_{A}^{0.6}},
$$

where $\phi_{B}$ is the association factor of water in salt solution; $\mu_{B}$ is the viscosity of water in salt solution $(\mathrm{kg}$ $\left.\mathrm{m}^{-1} \mathrm{~s}^{-1}\right) ; V_{A}\left(\mathrm{~m}^{3} \mathrm{~mol}^{-1}\right)$ is the molar volume of species at the boiling point; $M_{B}$ is the molecular weight of solvent $\left(\mathrm{kg} \mathrm{mol}^{-1}\right)$.

\section{Membrane mass transfer coefficient}

Mass transfer of water vapors through the pores of the membrane was mainly due to Knudsen diffusion (Knudsen number $(K n)$ for this study was 2.5 which confirms Knudsen regime flow). Thus, the mass transfer coefficient was estimated by applying Eq. (12) [30]:

$$
\begin{aligned}
k_{m}= & \frac{1}{R T}\left(\frac{D_{w}^{k} D_{w-a}^{0}}{D_{w-a}^{0}+p_{a} D_{w}^{k}}\right) \frac{M}{\delta}, \\
D_{w}^{k}= & \frac{2 \in r_{p}}{3 \tau} \sqrt{\frac{8 R T}{\pi M}}, \\
D_{w-a}^{0}= & -2.775 \times 10^{-6}+4.479 \\
& \times 10^{-8} T+1.656 \times 10^{-10} T^{2} .
\end{aligned}
$$

Here, $D_{w}^{k}\left(\mathrm{~m}^{2} \mathrm{~s}^{-1}\right)$ stands for the water Knudsen diffusion coefficient, $D_{w-a}^{0}\left(\mathrm{~m}^{2} \mathrm{~s}^{-1}\right)$ for the water-air diffusion coefficient, $T(\mathrm{~K})$ for the temperature along the membrane, $p_{a}(\mathrm{~Pa})$ for the partial pressure of air in the pores, $\tau$ for the tortuosity of the membrane $\left(\tau=\frac{1}{\varepsilon}\right), \in$ for the porosity of the membrane, $\delta(\mathrm{m})$ for the thickness of the membrane, $r_{p}(\mathrm{~m})$ for the pore radius $\left(2 \times 10^{-8}\right), M(\mathrm{~kg}$ $\mathrm{mol}^{-1}$ ) for the molar mass of water. Similarly, $R$ $\left(8.314 \mathrm{~J} \mathrm{~mol}^{-1} \mathrm{~K}^{-1}\right)$ denotes the universal gas constant. 
Thus, the overall mass transfer coefficient as described in Eq. (1) is estimated by the following correlation as described by Eq. (15) [31] $\left(\mathrm{m} \mathrm{s}^{-1}\right)$ :

$$
K_{o v}=\frac{1}{\left(P_{w, f}^{*} / k_{f}\right)+\left(1 / k_{m}\right)+\left(p_{w, o s}^{*} / k_{o s}\right)},
$$

where $P_{w, \text { os }}^{*}$ and $p_{w, f}^{*}(\mathrm{~Pa})$ are the pure water vapor pressures at the osmotic solution and feed solution side of the membrane, respectively. $k_{f}, k_{m}$, and $k_{o s}\left(\mathrm{~m} \mathrm{~s}^{-1} \mathrm{~Pa}^{-1}\right)$ are mass transfer coefficients in the shell (feed) side, within the membrane, and in the fiber (osmotic solution), respectively.

The relationship between the vapor pressure of water $\left(P^{*}\right.$, in $\left.\mathrm{mmHg}\right)$ and the temperature of the solution $\left({ }^{\circ} \mathrm{C}\right)$ is empirically given by Eq. (16) [32]:

$$
P^{*}=10^{8.07131-(1730.63 /(233.426+T))} \text {. }
$$

\section{Concentration polarization}

The concentration polarization is described by the creation of polarization (boundary) on either side of the membrane surface due to solute accumulation. The concentration polarization effects are considered significant on flux decline during the OMD process [33, 34]. The concentration at the feed-membrane interface as well as the osmotic solution-membrane interface can be obtained using the film theory (Eq. (17)) [35]:

$$
C_{m, i}=C_{b, i} \exp \left(\frac{J_{w} \delta}{D_{i} \rho_{i}}\right),
$$

where the subscript $i$ can be feed or osmotic solution. Boundary layer thickness (BLT) denoted by $\delta(m)$ is unknown and can be estimated from Eq. (18) according to the film-diffusion mass transfer coefficient and Sherwood number:

$$
\delta=\frac{D_{i}}{k_{i}}
$$

where $D_{i}$ is the diffusion coefficient $\left(\mathrm{m}^{2} \mathrm{~s}^{-1}\right.$ ) (feed or osmotic agent) calculated from Eq. (11) and $k_{i}$ is the mass transfer coefficient $\left(\mathrm{m} \mathrm{s}^{-1}\right)$ (feed or osmotic agent).

Then, the concentration polarization coefficient (CPC) at the feed as well as osmotic solution side is calculated from Eqs. (19) and (20) [36]:

$$
(\mathrm{CPC})_{f}=\frac{C_{m, f}}{C_{b, f}},
$$

$$
(\mathrm{CPC})_{\mathrm{os}}=\frac{C_{b, \mathrm{os}}}{C_{m, \mathrm{os}}} .
$$

\section{Heat transfer coefficients}

Feed, as well as osmotic solution side heat transfer coefficients (h, $\mathrm{W} \mathrm{m}{ }^{-2} \mathrm{~K}^{-1}$ ) were estimated using Eqs. (21-23) [25, 37]:

$$
\begin{aligned}
& h=\frac{\mathrm{Nu} k_{i}}{d_{i}} \\
& N u=1.86\left(\operatorname{Re} \operatorname{Pr} \frac{d_{i}}{l}\right)^{0.33}\left(\frac{\mu_{i}}{\mu_{w}}\right)^{0.14} \\
& \operatorname{Pr}=\frac{C_{p} \mu}{k_{f}},
\end{aligned}
$$

where $\mathrm{Nu}$ and $\mathrm{Pr}$ denote the Nusselt and Prandtl numbers (dimensionless), respectively; $k_{i}$ is the thermal conductivity of the fluid ( $\left.\mathrm{W} \mathrm{m}^{-1} \mathrm{~K}^{-1}\right) ; d_{i}(\mathrm{~m})$ is the characteristic length for the feed (fiber side). Similarly, $d_{h}$ is the hydraulic diameter for the osmotic solution shell side. $\mu$ and $\mu_{w}$ are the viscosities of the salt solutions (feed or osmotic solution) and pure water, respectively. $C_{p}$ is the heat capacity $\left(\mathrm{J} \mathrm{K}^{-1}\right)$.

\section{Membrane side heat transfer coefficient}

Heat transfer through the pores of the membrane takes place due to conduction in the form of sensible as well as latent heat when water vapors diffuse through the pores of the hydrophobic membrane [19]:

$$
\begin{aligned}
& h_{c}=\frac{k_{m}}{\delta}=\frac{k_{g}+(1-) k_{s}}{\delta}, \\
& h_{v}=\frac{J_{w} \Delta H_{v}}{\Delta T_{w}},
\end{aligned}
$$

where $k_{m}, k_{g}, k_{s}$ are the thermal conductivities of the membrane, the air, and the solid phase of the membrane, respectively (values taken from the literature [38]); $\Delta H_{v}$ is the latent heat of vaporization $\left(\mathrm{J} \mathrm{kg}^{-1}\right) ; \Delta T_{w}$ is the temperature difference $(K)$ among the temperature near the membrane wall on the feed side $\left(T_{f w}\right)$ and the osmotic solution side $\left(T_{p w}\right) ; \delta$ is the thickness of the membrane, and $\in$ is the porosity of membrane.

\section{Temperature polarization}

The temperature polarization would also contribute to the reduction of driving force which ultimately reduces the transmembrane flux. The decline in the driving force due to temperature polarization can be estimated by the 
temperature polarization coefficient (TPC) $[33,34]$. The temperature polarization effect on water transport flux is evaluated by calculating the temperature at the membrane-fluid interface on the feed as well as on the osmotic solution side (Eqs. (26-28)). Then, using Eq. (28), the temperature polarization coefficient (TPC) was calculated [19]:

$$
\begin{aligned}
& \Delta T_{w}=T_{f w}-T_{p w}, \\
& T_{f w}=T_{f}-\left(T_{f}-T_{p}\right)\left(\frac{\frac{1}{h_{f}}}{\frac{1}{h_{c}+h_{v}}+\frac{1}{h_{f}}+\frac{1}{h_{p}}}\right), \\
& T_{p w}=T_{p}+\left(T_{f}-T_{p}\right)\left(\frac{\frac{1}{h_{p}}}{\frac{1}{h_{c}+h_{v}}+\frac{1}{h_{f}}+\frac{1}{h_{p}}}\right), \\
& \operatorname{TPC}=\frac{\Delta T_{w}}{T_{f}-T_{p}} .
\end{aligned}
$$

\section{Physical properties of feed and osmotic solutions}

Density and viscosity correlations for the feed solution containing $\mathrm{Na}_{2} \mathrm{CO}_{3}$ as a solute in the range of 293-323 $\mathrm{K}$ and concentrations ranging from 1 to $6 \mathrm{~mol} \mathrm{~kg}^{-1}$ were calculated by the correlations found in the literature [39]:

$$
\begin{aligned}
& \rho(T, c)=\rho(T, 0) \sum_{i=0}^{4} \sum_{j=0}^{3} d_{i j}\left(\frac{c}{c^{*}}\right)^{i+1}\left(\frac{t}{T^{*}}\right)^{j}, \\
& \eta(T, c)=\eta(T, 0)\left(1+\sum_{i=0}^{4} \sum_{j=0}^{3} f_{i j}\left(\frac{c}{c^{*}}\right)^{i}\left(\frac{t}{T^{*}}\right)^{j},\right.
\end{aligned}
$$

where $c^{*}=1 \mathrm{~mol} \mathrm{~kg}{ }^{-1} ; T^{*}=1 \mathrm{~K} ; \mathrm{t}=\mathrm{T}-273.15 \mathrm{~K} ; \rho^{*}=1 \mathrm{~kg}$ $\mathrm{m}^{-3} \cdot d_{i j}$ and $f_{i j}$ are the correlation constants, their tabulated value can be found in the literature [39]; $\rho(T, 0)$ and $\eta(T, 0)$ is density and viscosity of pure of water at temperature $T$ and at atmospheric pressure.

\section{Density and viscosity of osmotic solution}

The correlations developed by Simion et al. [40] were applied to calculate the density and viscosity of osmotic solution containing $\mathrm{NaCl}$ as a solute in the temperature range of $293-333 \mathrm{~K}$ and concentration range of $1-6 \mathrm{~mol}$ $\mathrm{kg}^{-1}$ :

$$
\rho_{s o l}\left(X_{B}, T\right)=\rho_{H 2 O}(T) \sum_{i=0}^{3} \rho_{i}\left(\frac{X_{B}}{1-X_{B}}\right)^{i},
$$

$$
\mu_{\mathrm{NaCl}}=10^{-3} \times \exp (0.3719 * C) \times \exp \left(\frac{2068.075}{T}\right)
$$

In Eqs. (32) and (33), $X_{B}$ is the mole fraction of $\mathrm{NaCl}$ in the osmotic solution; and $C$ is the molar concentration of $\mathrm{NaCl}$ in the osmotic solution $\left(\mathrm{mol} \mathrm{L}^{-1}\right)$.

\section{Activity coefficient of salts solutions}

Activities of aqueous solutions of $\mathrm{Na}_{2} \mathrm{CO}_{3}$ and $\mathrm{NaCl}$ were calculated from Debye and Hückel's model [41]:

$$
\begin{aligned}
& \ln \left(X_{w} \gamma_{w}\right)=-m_{s} v \cdot M_{s}\left[1-\frac{\alpha}{3}\left|Z_{+} Z_{-}\right| \sqrt{I} \delta(\beta a \sqrt{I})+\frac{\delta I}{2}\right] \\
& I=\frac{1}{2}\left|Z_{+} Z_{-}\right| M_{s},
\end{aligned}
$$

where $\gamma_{w}$ is activity coefficient of aqueous salt solution $\left(\mathrm{Na}_{2} \mathrm{CO}_{3} / \mathrm{NaCl}\right) ; m_{s}$ is the molecular weight of solvent (water in this case: $0.018 \mathrm{~kg} \mathrm{~mol}^{-1}$ ) $\mathrm{Ms}$ is the molality of aqueous salt solutions $\left(\mathrm{Na}_{2} \mathrm{CO}_{3} / \mathrm{NaCl}\right)\left(1-6 \mathrm{~mol} \mathrm{~kg}^{-1}\right)$.

$\left|Z_{+} Z_{-}\right|$is the product of positive and negative charges; $I=$ ionic strength of the electrolytic solution, $\delta=0.1$ $\left|Z_{+} Z_{-}\right| ; \quad v$ (no. of cations and ions in electrolyte solution) $=v^{+}+v^{-} ; a, \beta$ are parameters dependent on temperature and are related to the average hydrated radius of ions, $(a \beta=1$ as previously suggested [41]).

\section{Membrane area calculations}

One of the practical aspects of applying the membrane process for salt recovery is based on the required membrane area. In this context, the model was applied to calculate the membrane area required to concentrate feed solution to the saturation point $\left(216 \mathrm{~g} \mathrm{~L}^{-1}\right)$ in a single pass. An overall mass balance for the feed flow rate and the salt mass balance was applied. Overall mass balance for the feed side is presented in Eq. (36):

$$
Q_{w}^{e v p}=Q_{f, \text { in }}-Q_{f, \text { out }}
$$

Salt transport balance is presented in Eqs. (37) and (38):

$$
\begin{aligned}
& Q_{w}^{\text {evp }}(0)=Q_{f, \text { in }} C_{f, \text { in }}-Q_{f, \text { out }} C_{f, \text { out }} \\
& Q_{f, \text { out }}=\frac{Q_{f, \text { in }} C_{f, \text { in }}}{C_{f, \text { out }}} .
\end{aligned}
$$

Here, $C_{f \text {,out }}$ is the maximum concentration of the salt, after which it cannot be dissolved anymore in the solution at a given temperature and hence crystallizes (216 g $\mathrm{L}^{-1}$ ) for $\mathrm{Na}_{2} \mathrm{CO}_{3} \cdot 10 \mathrm{H}_{2} \mathrm{O}$ (saturation concentration). So, it can be written as: $C_{f \text {,out }}=C_{f \text {,sat. }}$ 


$$
Q_{w}^{\text {evp }}=Q_{f, \text { in }}\left(1-\frac{C_{f, \text { in }}}{C_{f, \text { out }}}\right) .
$$

Inserting Eqs. (1) and (40), the area of the membrane required for the concentration of salt from the initial concentration $\left(C_{f \text {,in }}\right)$ to the saturation concentration $C_{f \text {,sat. }}$ can be calculated according to Eq. (40):

$$
A=\frac{Q_{w}^{\mathrm{evp}}}{J_{w}}=\frac{Q_{f, \text { in }}}{K_{o v}\left(P_{f}^{*} a_{f}-P_{s}^{*} a_{s}\right)}\left(1-\frac{C_{f, \text { in }}}{C_{f, \text { sat. }}}\right),
$$

where $Q_{w}^{\text {evp }}$ is the water removal rate $\left(\mathrm{L} \mathrm{h}^{-1}\right)$; $Q_{f \text {,in }}$ is the inlet flow rate $\left(\mathrm{L} \mathrm{h}^{-1}\right) ; Q_{f \text {,out }}$ is the feed outlet flow rate ( $\mathrm{L}$ $\left.\mathrm{h}^{-1}\right) ; C_{f, \text { in }}$ is the feed inlet concentration $\left(\mathrm{g} \mathrm{L}^{-1}\right) ; C_{f \text {, out }}$ is the feed outlet concentration $\left(\mathrm{g} \mathrm{L}^{-1}\right)$.

\section{Simulations and model algorithm}

The developed model equations were solved in MAT$\mathrm{LAB}^{\circledR} 2017$ for the water flux through the membrane pores. The simulation algorithm was developed as shown in Fig. 3. The simulation was started with the initial values of feed $\left(50 \mathrm{~g} \mathrm{~L}^{-1}\right)$ and osmotic agent $\left(100 \mathrm{~g} \mathrm{~L}^{-1}\right)$ concentration, and temperature $(293 \mathrm{~K})$ values as a first estimate to calculate initial water flux. Then, the iterative loops were used to update the water flux till the desired iterations were achieved. The accuracy was set to $10^{-3}$ for a single loop with a total number of iterations reached 200 to reach the desired accuracy. Finally, the scaling up of the process was proposed by calculating the total membrane area required for large-scale operations using the mass and heat transfer coefficients calculated in this study.

\section{Results and discussion Model validation}

The simulation results for water transport flux across the porous membrane as a function of feed as well as osmotic solution were validated with the experimental results taken by Salmón et al. [25] under the same operating and module geometrical conditions. In both cases (experimental as well as simulation), the transmembrane water transport flux was studied as a function of species concentration in the feed and osmotic solution streams. It

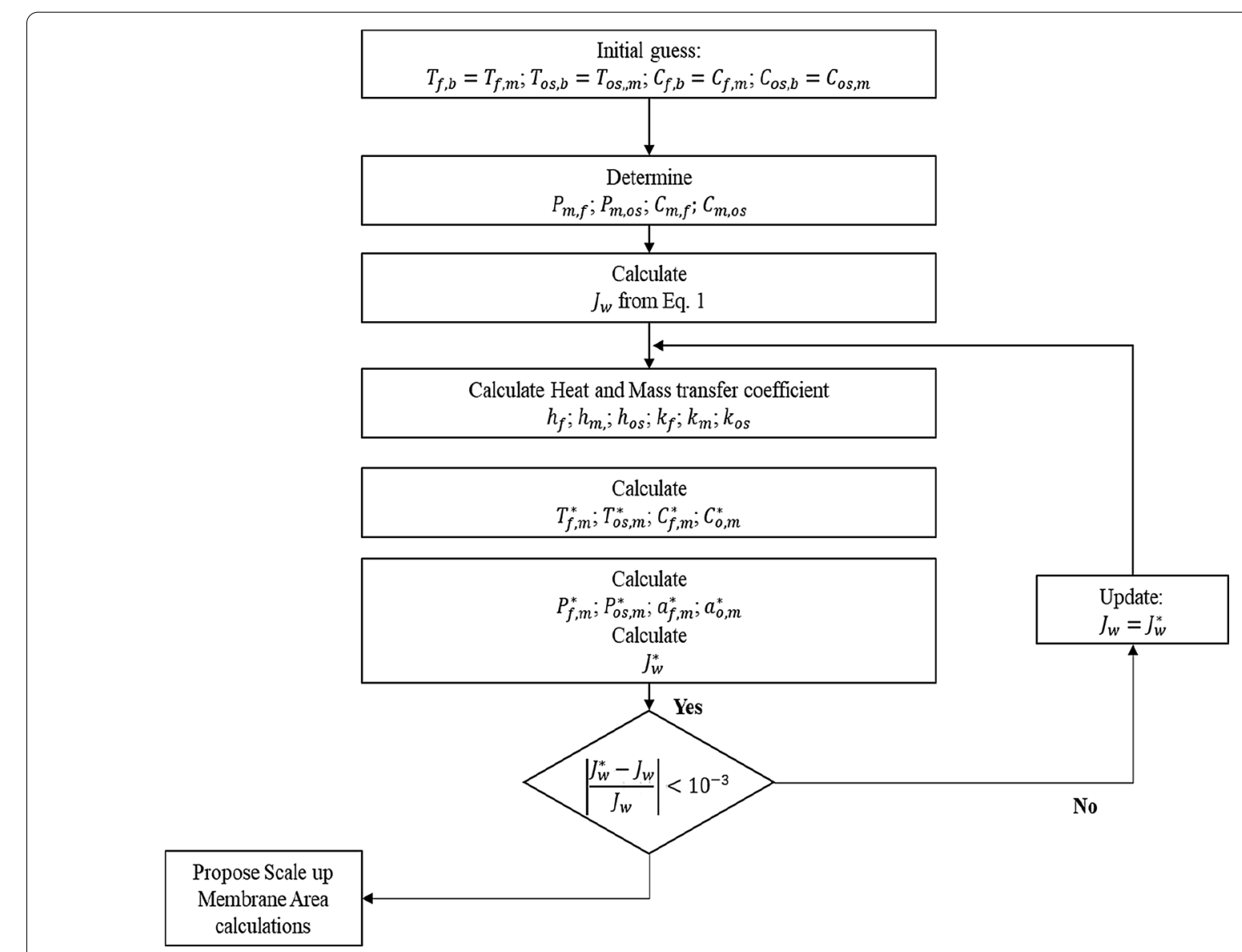

Fig. 3 Simulation algorithm for heat and mass transfer modeling in OMD 
can be seen from Fig. 4a and b, that in both cases (feed, as well as osmotic solution concentration, runs), simulation results are in good agreement with experimental data tested with the maximum deviation of $7 \%$. The reason for this deviation could be attributed to the assumptions taken during model development, such as the single-fiber approach or the activity correlations used for the physical properties of the salt solutions. Experimental errors could also contribute to explain this deviation. Nevertheless, the simulated water transport fluxes were also in the range as studied by Luis et al. [42] for the similar inorganic salts recovery using brine solution in OMD processes. Later, the model was applied to study the effect of main parameters like feed and osmotic solution flow rates, feed temperature, the effect of the hydrodynamic boundary layer as well as temperature and concentration polarization on transmembrane water transport flux.

Table 2 gives a comparison between the present work and some of the previous works performed on membrane crystallization for the recovery of various salts. One point
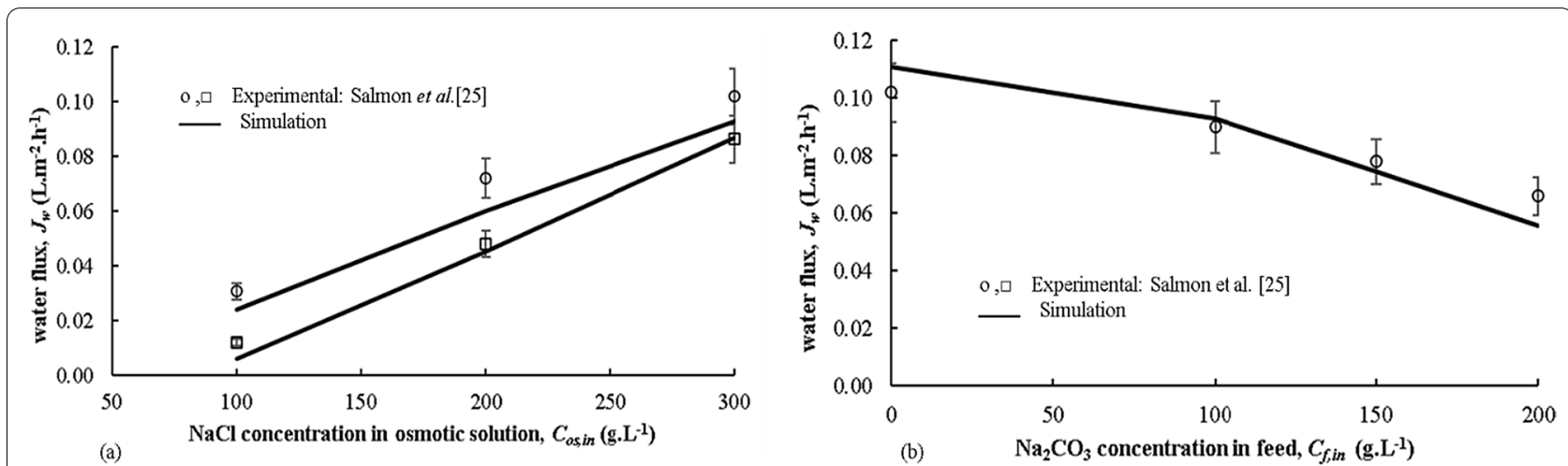

Fig. 4 Model validation with experimental data from Salmón et al. [25]; a effect of osmotic solution concentration $\left(C_{o s, i n}\right)$ on water flux; $C_{f, i n}=300 \mathrm{~g}$ $\mathrm{L}^{-1}$. o: $C_{\mathrm{os}, \mathrm{in}}=0 \mathrm{~g} \mathrm{~L}{ }^{-1}, \square: C_{\mathrm{os}, \mathrm{in}}=150 \mathrm{~g} \cdot \mathrm{L}^{-1}$. b Effect of feed concentration $\left(C_{f, \text { in }}\right)$ on water flux, $Q_{f, \text { in }}=27 \mathrm{~L} \mathrm{~h} \mathrm{~h}^{-1}, \mathrm{Q}_{\mathrm{os}, \mathrm{in}}=18 \mathrm{~L} \cdot \mathrm{h}^{-1}, T_{f}=T_{\mathrm{os}}=293 \pm 1 \mathrm{~K}$

Table 2 Comparative analysis of the present work with literature

\begin{tabular}{|c|c|c|c|c|c|c|}
\hline Feed & Crystal product & Membrane & Pore size $(\mu \mathrm{m})$ & Operating conditions & Water flux $\left(\mathrm{L} \mathrm{m}^{-2} \mathrm{~h}^{-1}\right)$ & Ref. \\
\hline $\mathrm{NaCl}$ solution & $\mathrm{NaCl}$ & PVDF & 0.0082 & $\begin{array}{l}\mathrm{NaCl} \text { concentration: } 250 \mathrm{~g} \mathrm{~L}^{-1} \\
\text { Temp: } 20^{\circ} \mathrm{C} \\
\text { NaCl solution flowrate: } 9.44 \\
\mathrm{~m}^{3} \mathrm{~h}^{-1}\end{array}$ & $0.86-2.77$ & [14] \\
\hline $\begin{array}{l}\text { Solution with } \mathrm{NaCl} \text {, } \\
\mathrm{CaCl}_{2}, \mathrm{MgCl}_{2} \text { and } \\
\mathrm{MgSO}_{4}\end{array}$ & $\mathrm{NaCl}$ and $\mathrm{MgSO}_{4} \cdot 7 \mathrm{H}_{2} \mathrm{O}$ & PP & 0.2 & $\begin{array}{l}\mathrm{NaCl} \text { concentration: } \\
50-350 \mathrm{~kg} \mathrm{~m}^{-3} \\
\text { Temp: } 40^{\circ} \mathrm{C}\end{array}$ & $0.25-0.45$ & [7] \\
\hline $\begin{array}{l}\text { Solution with } \mathrm{NaCl} \text {, } \\
\mathrm{CaCO}_{3}, \mathrm{Na}_{2} \mathrm{CO}_{3} \text { and } \\
\mathrm{MgSO}_{4}\end{array}$ & $\begin{array}{l}\mathrm{NaCl}, \mathrm{CaCO} 3, \mathrm{Na}_{2} \mathrm{CO}_{3} \\
\text { and } \mathrm{MgSO}_{4}\end{array}$ & PP & 0.2 & $\begin{array}{l}\text { Brine concentration: } \\
\quad 68-215 \mathrm{~g} \mathrm{~L}^{-1} \\
\text { Feed temp: } 35^{\circ} \mathrm{C} \\
\text { Feed flowrate: } 75-532 \\
\mathrm{~m}^{3} \mathrm{hr}^{-1}\end{array}$ & - & [43] \\
\hline Solution of $\mathrm{NaCl}$ & $\mathrm{NaCl}$ & PVDF & - & $\begin{array}{l}\mathrm{NaCl} \text { concentration: } 264 \mathrm{~g} \mathrm{~L}^{-1} \\
\text { Temp: } 40-70^{\circ} \mathrm{C} \\
\mathrm{NaCl} \text { solution Flow velocity: } \\
0.5 \mathrm{~m} \mathrm{~s}^{-1}\end{array}$ & $0.8-8.4$ & [44] \\
\hline $\mathrm{Na}_{2} \mathrm{SO}_{4}$ solution & $\mathrm{Na}_{2} \mathrm{SO}_{4}$ & PVDF & 0.22 & $\begin{array}{l}\mathrm{Na}_{2} \mathrm{SO}_{4} \text { concentration: } 284 \mathrm{~g} \\
\mathrm{~L}^{-1} \\
\mathrm{Temp}: 40-70^{\circ} \mathrm{C} \\
\mathrm{Na}_{2} \mathrm{SO}_{4} \text { solution flow velocity: } \\
0.057 \mathrm{~m} \mathrm{~s}^{-1}\end{array}$ & $1.9-11.87$ & {$[45]$} \\
\hline $\mathrm{Na}_{2} \mathrm{CO}_{3}$ solution & $\mathrm{Na}_{2} \mathrm{CO}_{3}$ & PP & 0.04 & $\begin{array}{l}\mathrm{Na}_{2} \mathrm{CO}_{3} \text { concentration: } \\
50-200 \mathrm{~g} \mathrm{~L}^{-1} \\
\text { Temp: } 40-70{ }^{\circ} \mathrm{C} \\
\mathrm{Na}_{2} \mathrm{CO}_{3} \text { solution flowrate: } \\
0.0012-0.003 \mathrm{~m}^{3} \mathrm{~h}^{-1}\end{array}$ & $0.027-0.151$ & Present work \\
\hline
\end{tabular}


should be kept in mind, that the efficiency of the membrane crystallization process largely depends on the type of salt to be recovered, membrane module, membrane characteristics, and the operating parameters. The lower water flux in the present work can be mainly attributed to the lower pore size of the PP membrane, as well as the large molecular size of $\mathrm{Na}_{2} \mathrm{CO}_{3}$ crystals, that causes hindrance to the transfer of water molecules. Another reason is the lower feed flowrates used in this study as compared to the previous ones.

\section{Vapor pressure profiles at the feed as well as osmotic solution side}

The vapor pressure profiles shown in Fig. 5 were plotted based on Raoult's law. The vapor pressure was considered as the function of concentration and temperature. From Fig. 5, it can be seen that due to relatively low feed concentration $\left(100 \mathrm{~g} \mathrm{~L}^{-1}\right)$ and higher temperature $(313 \pm 1 \mathrm{~K})$, the vapor pressure is higher in comparison to the osmotic solution side, having a higher concentration $\left(300 \mathrm{~g} \mathrm{~L}^{-1}\right)$ and low temperature $(293 \pm 1 \mathrm{~K})$. This difference in concentration and temperature between feed and osmotic solutions causes the gradient for the vapor transport across the membrane from the feed side to the osmotic solution side. However, it should be noted that at the feed-membrane interface, the vapor pressure tends to decrease due to concentration and temperature polarization effects (these effects are discussed in detail in "Effect of process parameters on overall" section). Furthermore, it can be observed that there is a sudden jump in the vapor pressure, which indicates the vapor pressure of pure water at the membrane pore entry (due to the hydrophobic nature of the membrane). Similar trends were also observed at the membrane-osmotic solution interface. This difference between the vapor pressure of pure water at the membrane pore entry and

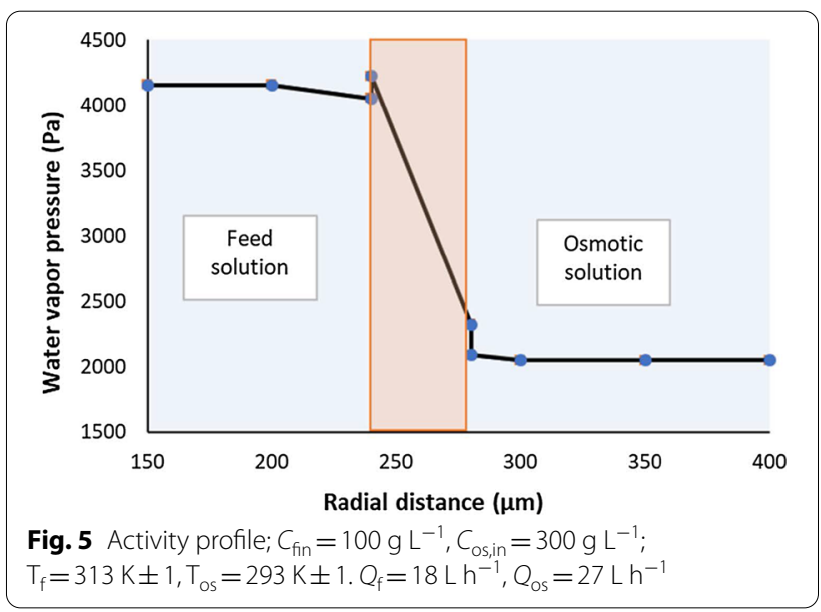

the solution vapor pressure at the membrane interface (termed as vapor pressure lag) is very critical for practical applications of the OMD process. The lower the value of the vapor pressure leg, the higher will be the process efficiency.

\section{Effect of species concentration in feed and osmotic solution streams}

Simulation runs were performed to study the effect of species concentration in feed and osmotic solution streams on transmembrane water transport flux. Results of water flux vs species concentration in feed and osmotic solution are shown in Fig. 6. It can be observed from Fig. 6a, that with varying feed concentration from 50 to $200 \mathrm{~g} \mathrm{~L}^{-1}$, the water transport flux was decreased by $50 \%$. The decrease in water flux was related to the fact that, for an increase in feed concentration, the water activity at the feed side was decreased, and hence, the gradient for water transport was reduced. Similar trends were also observed by Salmón et al. [25] and Martínez et al. [14] for the concentration of $\mathrm{Na}_{2} \mathrm{CO}_{3}$ in pharmaceutical products recovery using OMD.

Simulations were performed varying the osmotic solution concentration from 100 to $300 \mathrm{~g} \mathrm{~L}^{-1}$ to study the effect of osmotic solution concentration on transmembrane water flux. As shown in Fig. 6b, the water transport flux was enhanced by $200 \%$ at a higher osmotic solution concentration. The increase in flux was due to a decrease in water activity at the osmotic solution side at higher osmotic solution concentration. The overall mass transport gradient was thus, increased, resulting in enhanced water flux. The effects of osmotic solution concentration were previously studied by Luis et al. [42] and Salmón et al. [24]. Similar trends of water flux as a function of osmotic solution concentration were reported in this study.

\section{Effect of feed and osmotic solution flow rates on transmembrane water flux}

The water transport flux through the membrane was studied as a function of feed and osmotic solution flow rates. For both cases, water transport flux was studied at different solution concentrations. Results are presented in Fig. 7. It can be observed that in both the cases (feed and osmotic solution), at very low flow rates $\left(1.2 \mathrm{~L} \mathrm{~h}^{-1}\right)$, the transmembrane water flux was minimum. This effect could be attributed to the formation of a concentration/temperature polarization boundary layer(s) at very low flow rates [19, 38]. A hydrodynamic boundary layer is built, caused by a concentration/temperature difference between bulk and the membrane surface termed as polarization. This effect can lead to accumulation of species concentration build-up on the membrane surface, 


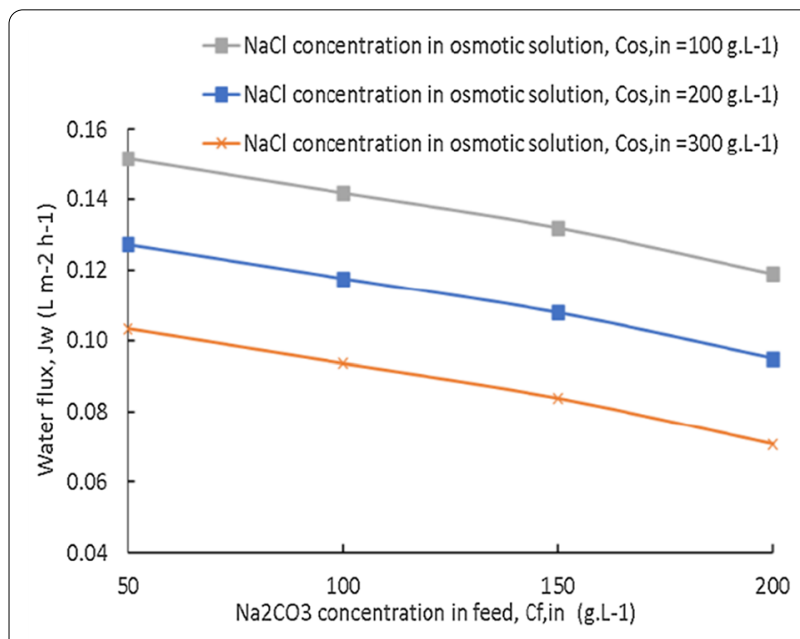

(a)

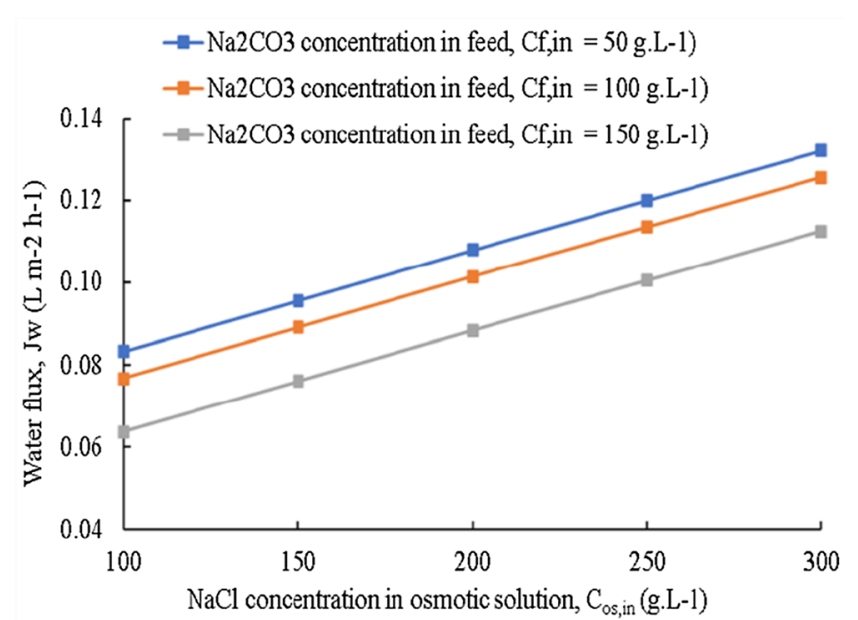

(b)

Fig. 6 Water transport flux as a function of a solute concentration in feed, $C_{f, i n}$ and $\mathbf{b}$ solute concentration in osmotic solution, $C_{o s, i n} \cdot Q_{f}=21 L^{-1}$; $Q_{\mathrm{os}}=24 \mathrm{Lh}^{-1} ; T_{f}=298 \mathrm{~K} \pm 1 ; T_{\mathrm{os}}=293 \mathrm{~K} \pm 1$
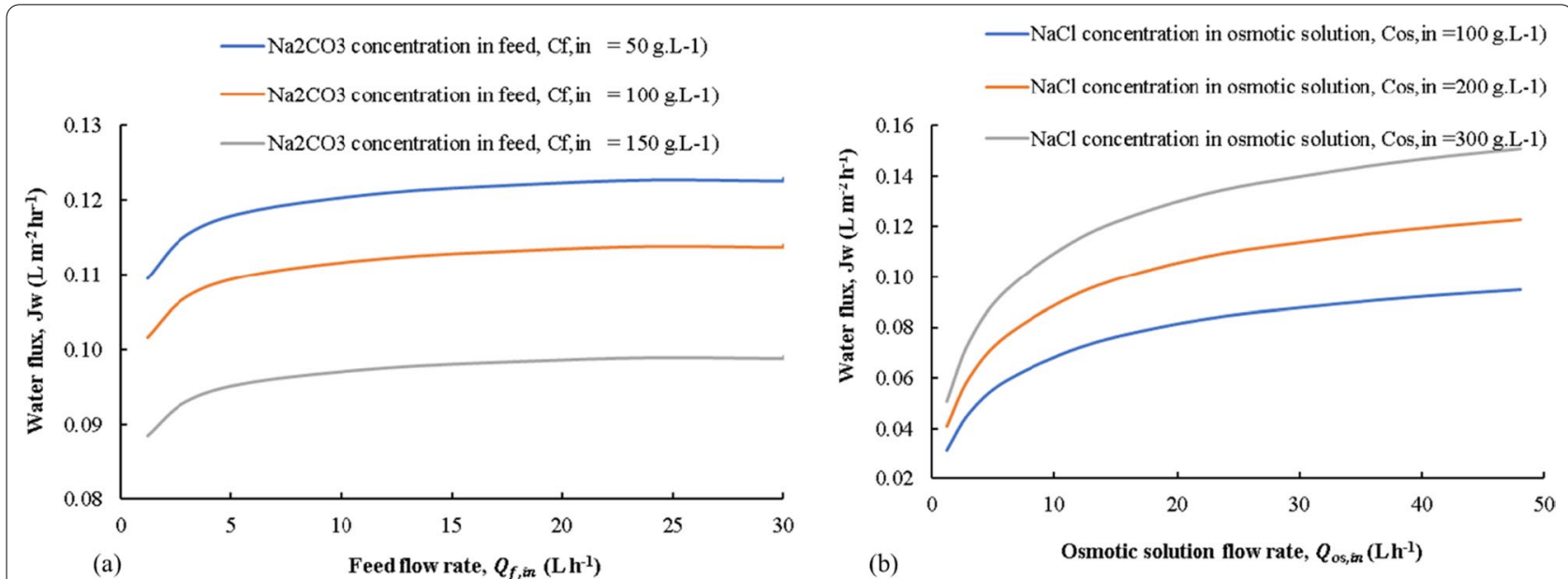

Fig. 7 Water transport flux as a function of feed and osmotic solution flow rate. Conditions: for a osmotic solution concentration, $C_{0 \text { s,in }}=300 \mathrm{~g} \mathrm{~L}^{-1}$; For b feed concentration, $C_{\text {os, } i n}=150 \mathrm{~g} \mathrm{~L}^{-1} ; T_{f}=303 \mathrm{~K} \pm 1, T_{\text {os }}=293 \mathrm{~K} \pm 1$

particularly at high feed/osmotic solution concentration, consequently developing the salt crystals [46-48]. Polarization effects can be reduced by creating turbulence. From Fig. 7a, it can be seen that as the feed flow rate is increased from 1.2 to $3 \mathrm{~L} \mathrm{~h}^{-1}$, the water flux is enhanced because of the reduction in polarization layer thickness. At a feed flowrate of $6 \mathrm{~L} \mathrm{~h}^{-1}$, a steady-state flux was achieved and a further increase in feed flow rate had no significant effect on water transport flux. This effect could be related to a high reduction in the boundary layer thickness. Indeed, $R e$ calculated for a single fiber (flowcell) was between 0.076 and 1.400 for the flow rate ranging from 1.2 to $24 \mathrm{~L} \mathrm{~h}^{-1}$, ensuring laminar flow conditions
$(\operatorname{Re}<1)$ [49]. These results conclude that the flow rate was not sufficient to further reduce the boundary layer.

For the osmotic solution (Fig. 7b), steady-state conditions for water flux were achieved at high flow rates than those at high feed flow rates. The complex structure of shell (flow-cell) and then the polarization effects are higher for the osmotic solution flow in shell side as compared to the feed side (lumen side) flow. The effect of osmotic solution flow rate on water flux was previously studied by Ravindra Babu et al. [34]. It was observed that the osmotic solution flow rate enhanced the water flux for the range of flow rates studied for pine juice concentration. 
In a nutshell, it can be inferred that at lower feed or osmotic solution flow rates, the effect of the polarization layer is higher, and a threshold flow rate should be maintained to minimize these effects.

\section{Effect of feed temperature}

Feed temperature is a key process parameter in OMD, as feed temperature directly influences the vapor pressure at the feed side, creating a vapor pressure gradient across the membrane. However, its effect on OMD performance should be studied in detail. The increase in feed temperature is an energy-consuming step and it is directly related to overall process cost.

Water flux simulations were performed at different feed and osmotic solution concentrations to study the effect of feed temperature. The results for water flux as a function of feed temperature for various species concentrations in feed and osmotic solutions are shown in Fig. 8. It can be observed that when the temperature was increased from 293 to $313 \mathrm{~K}$, the water flux increased linearly because of the increase in the driving force (vapor pressure increases at the feed side). It was also noted from Fig. 8a that for different feed concentrations, the water flux was lower at higher feed concentration because of the decrease in the water activity at the feed side. This effect was more prominent in the temperature range of 293 to $303 \mathrm{~K}$ and became negligible at $313 \mathrm{~K}$. The reason for this effect is that at low temperatures, the gradient was influenced by activity changes. However, at higher temperatures, the pressure gradient dominated the process, and the effect of feed concentration became negligible. Similar trends have been observed by Khalifa et al. [21] and Xu et al.
[50] for direct contact membrane distillation in water desalination.

On the other hand, for different osmotic solution concentration simulation runs as shown in Fig. 8b, the highest flux was achieved with higher osmotic solution concentration. Due to the lower osmotic activities at higher osmotic solution concentrations, the vapor pressure gradient across the membrane was enhanced. These results support the fact that the water flux was directly affected by feed temperature and that feed concentration affects the water flux at low vapor pressure gradients. Nevertheless, an increase in osmotic solution concentration enhanced the water flux.

\section{Effect of process parameters on overall mass transfer coefficient}

Effect of important parameters like osmotic solution concentrations, feed, and osmotic solution flow rates and feed temperature on overall mass transfer coefficient (MTC) was also studied. Simulation results are shown in Fig. 9a-d. From Fig. 9a, it can be observed that with the increase in osmotic solution concentration, the overall MTC was reduced. It is indicated that when the osmotic concentration was increased from 100 to $300 \mathrm{~g} \mathrm{~L}^{-1}$, the overall MTC was reduced by $40-50 \%$. With the increase in osmotic solution concentration, the water transport flux was enhanced, as explained in previous sections, leading to an increase in the thickness of the polarization layer either caused by temperature or concentration changes. Indeed, the concentration polarization coefficient (CPC) was calculated according to Eq. 20, and it was only between 1.0 and 1.2 for osmotic solution concentration values ranging between 100 and $300 \mathrm{~g} \mathrm{~L}^{-1}$.

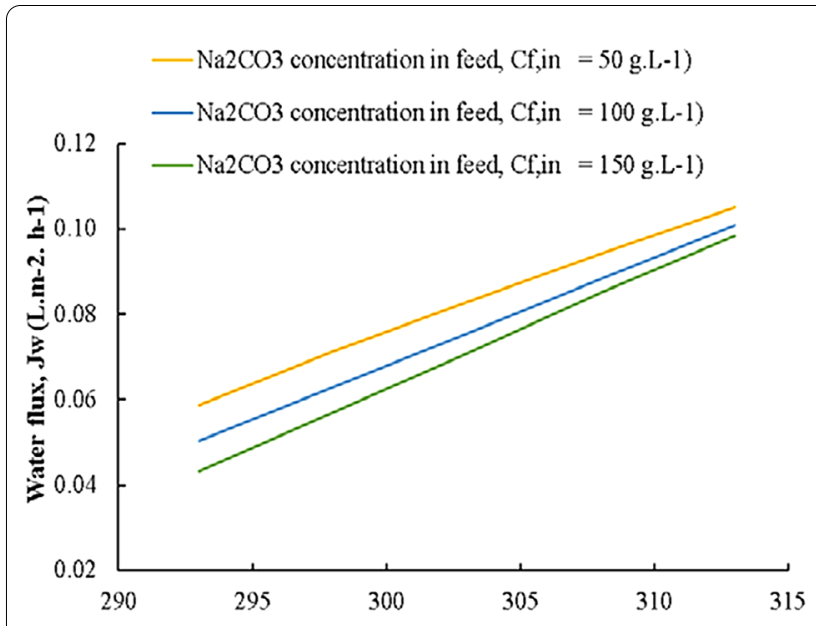

(a)

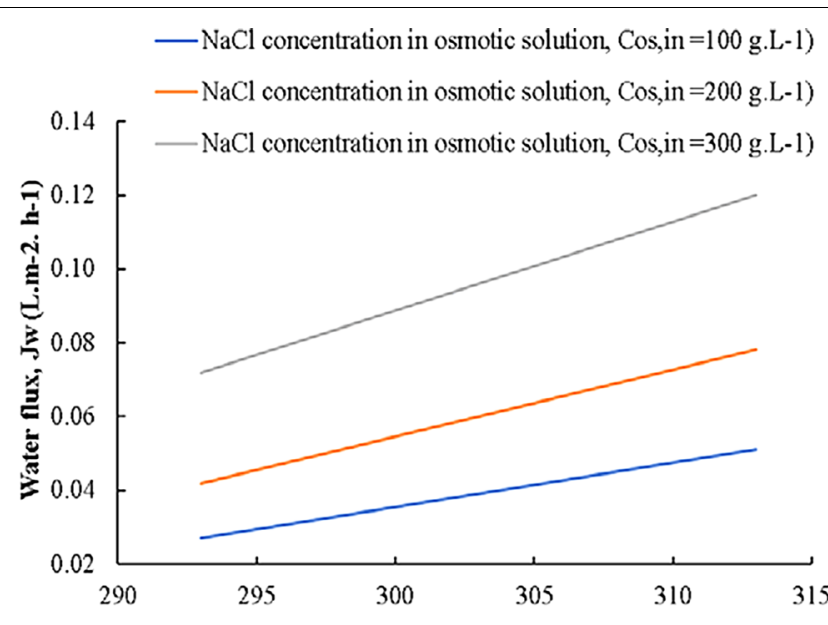

(b)

Feed Temperature, $\mathrm{T}(\mathrm{K})$

Fig. 8 Water transport flux as a function of feed temperature. Conditions: $Q_{f}=Q_{o s}=18 \mathrm{~L} \mathrm{~h}^{-1}$, For (a): osmotic solution concentration, $C_{\mathrm{os}, \mathrm{in}}=300 \mathrm{~g}$ $\mathrm{L}^{-1}$; For (b): feed concentration $C_{\mathrm{f}, \mathrm{in}}=150 \mathrm{~g} \mathrm{~L}^{-1}$ 


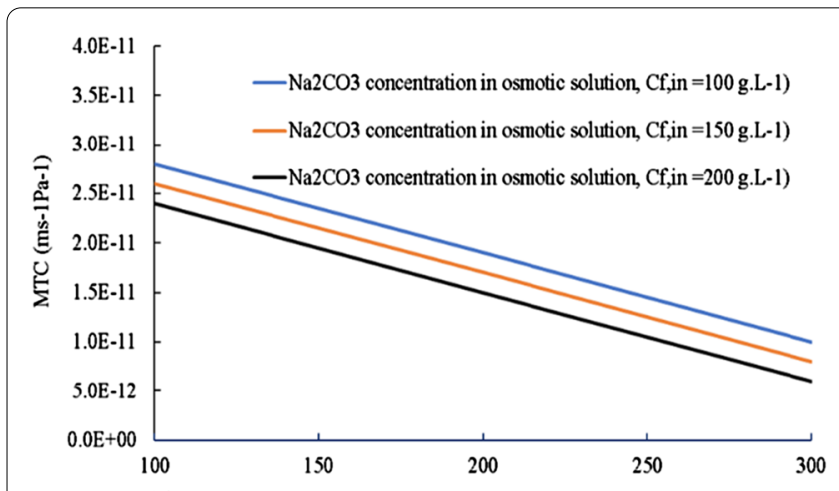

(a) $\mathrm{NaCl}$ concentration in osmotic soiution, $\mathrm{Cos}$,in (g.L-1)
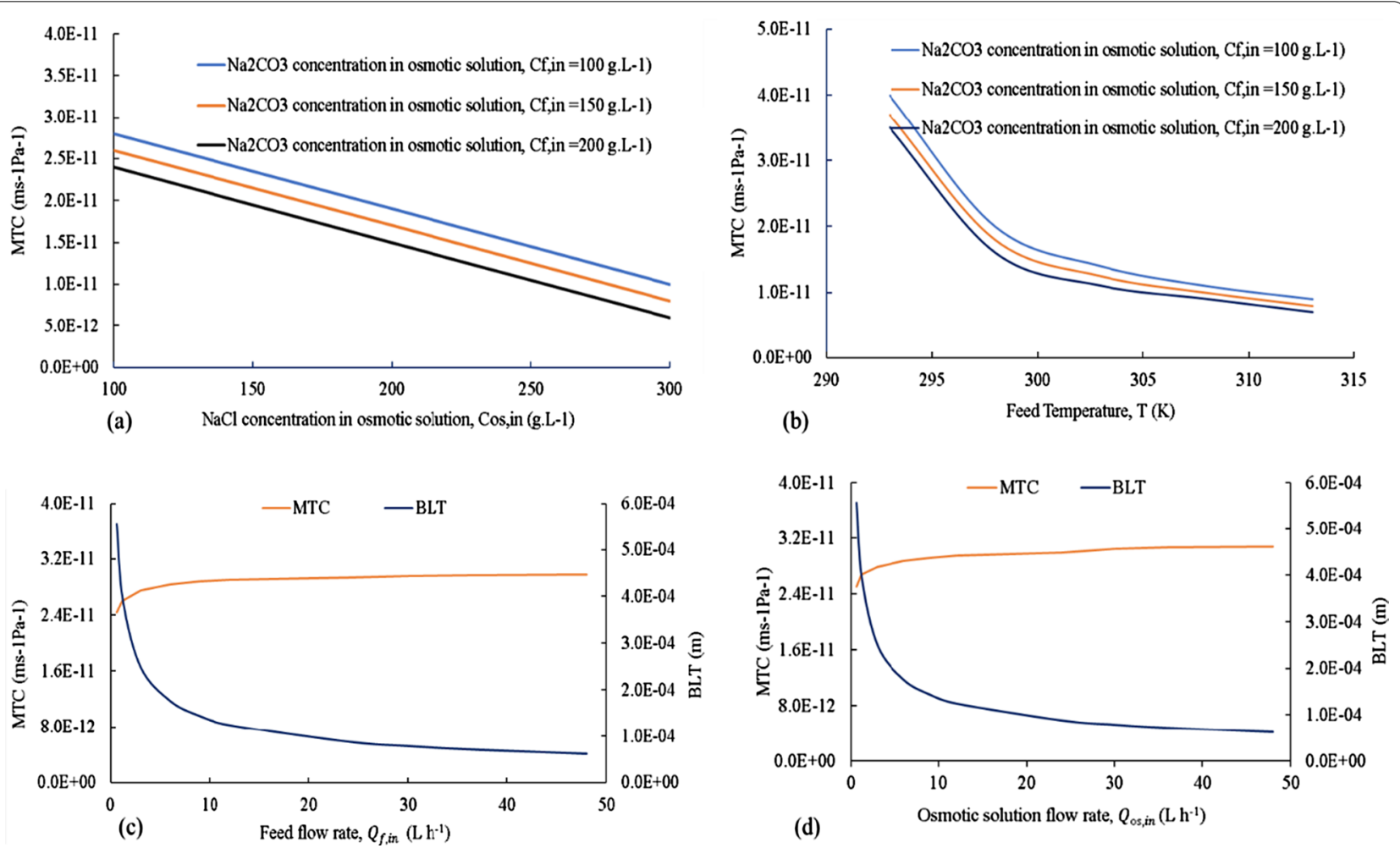

Fig. 9 Overall mass transfer coefficient as a function of a osmotic solution concentration, $C_{\text {osini }}$ b feed temperature, $T_{f i} \mathbf{c}$ feed flow rate, $Q_{\dot{f}} \mathbf{d}$ osmotic solution flow rate, $Q_{\text {os }}$

This result summarizes that concentration polarization effects were observed at high osmotic concentrations. The effect of concentration polarization in OMD has already been observed by different authors. For instance, Ravindra Babu et al. [34] found that concentration polarization hindered the overall mass transfer of high osmotic solution concentration. Similarly, Li et al. [51] observed a decrease in the overall mass transfer coefficient with an increase in the osmotic solution concentration. Therefore, experimental fluxes were lower than expected ones.

Similarly, it can be observed from Fig. $9 \mathrm{c}$ and d, that the boundary layer thickness (BLT) (m) was reduced significantly with an increase in the flow rate for both the cases, i.e.; feed as well as osmotic solution. However, a plateau reached a flow rate of 12 to $15 \mathrm{~L} \mathrm{~h}^{-1}$ and after that the BLT became negligible. These results conclude that to avoid boundary layer effects, a minimum flowrate of $12 \mathrm{~L}$ $\mathrm{h}^{-1}$ should be maintained at either side of the membrane (feed as well as the osmotic solution) under specified operating conditions for the studied HFMC module.

The effect of feed temperature on overall MTC was studied for different feed concentrations as shown in Fig. 9b. It can be seen that overall MTC decreased rapidly from $4.0 \times 10^{-11}$ to $1.5 \times 10^{-11} \mathrm{~m} \mathrm{~s}^{-1} \mathrm{~Pa}^{-1}$ when the feed temperature was increased from 293 to $298 \mathrm{~K}$. This decrease in overall MTC was probably due to the hightemperature polarization effect. High water transport flux was induced because of an exponential increase in vapor pressure at the feed side, increasing the heat transfer rate and ultimately causing temperature polarization. The effect of temperature polarization was stronger than that of concentration polarization because of the exponential curve of vapor pressure. Indeed, the temperature polarization coefficient calculated for this study was between 0.14 and 0.20 confirming the presence of temperature polarization, which affects the overall MTC as well as the water transport flux. Salmón et al. [24] observed the similar trends in OMD process.

The effect of feed and osmotic solution flow rates on overall MTC was also studied and shown in Fig. 9c and $\mathrm{d}$, respectively. The aim was to obtain the flow conditions at which polarization effects were reduced, and the transmembrane water flux was enhanced. The results showed that at very low flow rates $\left(1.2 \mathrm{~L} \mathrm{~h}^{-1}\right.$ ) in both cases (feed and osmotic solution streams), the overall MTC was low, and hence, boundary layer effects were dominant. However, as the flow rate was increased to $6 \mathrm{~L} \mathrm{~h}^{-1}$, the boundary layer thickness was reduced and the overall MTC reached a steady-state value. With a further increase in the flow rate, no significant change in overall MTC was 
observed, indicating that there was not enough turbulence to reduce the polarization effects.

\section{Membrane area requirements and proposed scaling up of the process}

The linear scale-up proposed here in this study is inspired by the experimental results of Salmón et al. [24]. They studied the salt recovery with a single module as well as two modules in series and observed similar trends for water flux as well as MTC. Hence, it was concluded that linear scale-up was possible. Simulation results from the model equations as developed in "Theory" section "theory", a total number of 136 HFMC modules of the same specifications as described in Table 1 were estimated to reach the saturation concentration $\left(216 \mathrm{~g} \mathrm{~L}^{-1}\right)$ in a single pass stage and for the feed flow rate of $24 \mathrm{~L} \mathrm{~h}^{-1}$. Likewise, the linear scale-up of the process was proposed by simulating the required membrane area at higher feed flow rates, which can be considered as industrial wastewater flow rates. Table 3 summarizes the membrane area requirements to the concentration of feed until its saturation for different flow rates. For the highest flow rate used $\left(2000 \mathrm{~L} \mathrm{~h}^{-1}\right)$, the required membrane area was $8500 \mathrm{~m}^{2}$, which corresponds to 6100 membrane modules (based on the effective surface area of a single module 1.4 $\mathrm{m}^{2}$ ). The space required to install this membrane facility would be $4.3 \mathrm{~m}^{3}$.

To design the membrane facility to treat these industrial flow rates several possibilities of membrane module configurations may be explored such as increasing the number of fibers or fiber lengths in a single module (which will certainly change the overall mass transfer coefficient) or the series/parallel combinations of the large number of modules having similar size and characteristics as of lab-scale module used as a reference for the calculation of area. The proposed scale-up approach used in this research work is based on a linear scale, which means that the mass transfer coefficient is assumed to be constant (modules with the same configuration as of lab-scale connected in series/parallel). For higher flow rates, it is distributed into different trays connected in parallel (a single tray consists of 136 modules connected in series). However, it is important to note that linear scale-up calculations presented here are for a rough estimation of the membrane area at scale-up conditions. For example, for practical implementation of the membrane plant setup, several parameters of the system do change with scaling up, such as lower thermal efficiency, heat losses, fouling phenomena, that consequently affect the process energy requirements and thus, the required membrane area for the particular application. Therefore, before implementing the OMD for salt recovery these factors should be considered. Nevertheless, due to the large specific surface area of HFMC modules $\left(2000 \mathrm{~m}^{2}\right.$ $\mathrm{m}^{3}$ ), the required volume for membrane installation facility is small $\left(0.1 \mathrm{~m}^{3}\right)$ in comparison with the conventional techniques used for inorganic salt concentration or crystallization such as industrial evaporators.

The effect of different conditions like feed concentration, feed flow rates, and feed temperature on the membrane area was also studied under other operating conditions. From the results (Fig. 10), it can be seen that with an increase in feed temperature, the membrane area can be reduced. Likewise, with an increase in feed flow rates and feed concentration, the membrane area was higher as predicted.

Furthermore, the quantitative effect of each parameter affecting the membrane area was studied using sensitivity analysis [16]. For each parameter, sensitivity coefficients were calculated; the results are shown in Table 4. It can be observed that for feed flow rate variation, the sensitivity coefficient was 1 , which means a linear increase. For variation in feed temperature, the sensitivity coefficient value varied from -1.5 ( $298 \mathrm{~K}$ ) to -2.77 (333 K) (the negative sign indicated an inverse relationship between the area and the parameter and thus a decrease in the membrane area). This shows a higher impact of feed temperature, particularly when operating at $333 \mathrm{~K}$. Similarly, the osmotic solution concentration also had a high impact in reducing the membrane area, while species concentration

Table 3 Membrane area calculated based on different flow rates. Under conditions: (feed concentration: $100 \mathrm{~g} \mathrm{~L}^{-1}$; feed temperature: $25^{\circ} \mathrm{C}$; osmotic solution concentration: $300 \mathrm{~g} \mathrm{~L}^{-1}$ )

\begin{tabular}{lllll}
\hline Feed flow rate, $\mathbf{Q}_{\boldsymbol{f}}\left(\mathbf{L} \mathbf{h}^{-\mathbf{1}}\right)$ & $\begin{array}{l}\text { Membrane area required } \\
\left(\mathbf{m}^{\mathbf{2}}\right)\end{array}$ & $\begin{array}{l}\text { No. of modules in series (per } \\
\text { tray) }\end{array}$ & $\begin{array}{l}\text { No. of trays required in } \\
\text { parallel }\end{array}$ & $\begin{array}{l}\text { Volume } \\
\text { required on } \\
\mathbf{s i t e}\left(\mathbf{m}^{\mathbf{3}}\right)\end{array}$ \\
\hline 24 & 190 & 136 & 1 & 0.1 \\
500 & 2130 & 136 & 11 & 1.1 \\
1000 & 4300 & 136 & 26 & 2.1 \\
1500 & 6400 & 136 & 34 & 3.2 \\
2000 & 8500 & 136 & 45 & 4.3 \\
\hline
\end{tabular}



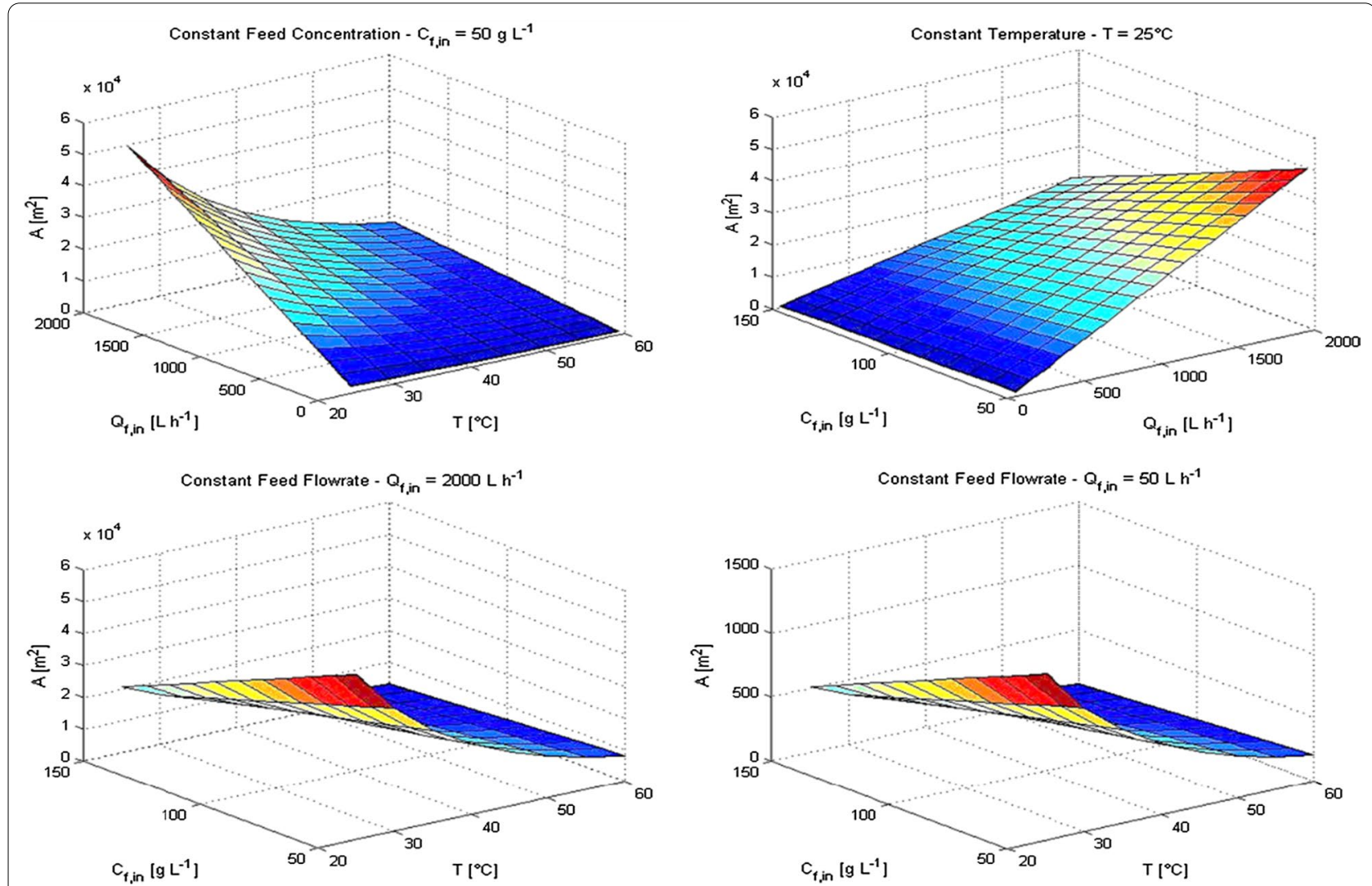

Fig. 10 Combined effects of operating parameters, feed temperature, feed flow rate, and initial feed concentration on membrane area

Table 4 Sensitivity analysis for different operating conditions

\begin{tabular}{|c|c|c|c|c|c|c|c|c|}
\hline \multirow{2}{*}{$\begin{array}{l}\text { Feed flow rate, } Q_{f} \\
\left(\mathrm{Lh}^{-1}\right)\end{array}$} & \multirow{2}{*}{$\begin{array}{l}\text { Feed conc } C_{f, \text { in }} \\
\left(\mathrm{g} \mathrm{L}^{-1}\right)\end{array}$} & \multirow{2}{*}{$\begin{array}{l}\text { Osmotic solution conc } \\
C_{o s}\left(g ~ L^{-1}\right)\end{array}$} & \multirow{2}{*}{$\begin{array}{l}\text { Feed } T \\
\mathrm{~T}_{\mathrm{f}, \text { in }}(\mathrm{K})\end{array}$} & \multicolumn{5}{|c|}{ Sensitivity coefficient } \\
\hline & & & & $T$ & $Q_{f o}$ & $C_{f o}$ & $C_{f, s a t}$ & $C_{o s}$ \\
\hline 2000 & 50 & 300 & 298 & -1.49 & 1 & -0.3 & 2.6 & -3.9 \\
\hline 2000 & 50 & 300 & 313 & -1.72 & 1 & -0.3 & 2.6 & -3.9 \\
\hline 2000 & 50 & 300 & 333 & -2.77 & 1 & -0.3 & 2.6 & -3.9 \\
\hline 2000 & 100 & 300 & 298 & -1.49 & 1 & -0.9 & 3.2 & -3.9 \\
\hline 2000 & 100 & 300 & 313 & -2.13 & 1 & -0.9 & 3.2 & -3.9 \\
\hline 2000 & 100 & 300 & 333 & -2.77 & 1 & -0.9 & 3.2 & -3.9 \\
\hline 2000 & 200 & 300 & 298 & -1.49 & 1 & -12 & 15 & -3.9 \\
\hline 2000 & 200 & 300 & 313 & -2.13 & 1 & -12 & 15 & -3.9 \\
\hline
\end{tabular}

in the feed stream had a lower impact at low species concentrations $\left(50 \mathrm{~g} \mathrm{~L}^{-1}\right)$. Based on these results, it can be concluded that osmotic solution concentration and feed temperature were the main parameters influencing membrane area requirements and that, to develop a system of OMD, these parameters need to be properly selected and optimized.

From the results stated in Tables 3 and 4, it can be concluded that the space required for the membrane installation facility was relatively smaller compared to conventional industrial equipment, even at the industrial flow rates. Nevertheless, membrane area and the space required for the installation facility can be further reduced by choosing the optimum operational parameters like feed temperature, feed concentration, and osmotic solution concentration.

OMD becomes a more viable option when the industrial effluents are received from the source at higher 
temperatures. For instance, for a case study of effluents coming from gas scrubber, Tun and Groth [52] found OMD coupled with $\mathrm{RO}$ as a practical option to implement. Similarly, osmotic solution concentration plays a key role in providing a continuous water transport flux and is one of the key parameters. Therefore, one of the important aspects of OMD process viability relies on the osmotic solution concentration. While considering treatment of industrial effluents, dilution of the osmotic solution takes place and thus continuous regeneration is required, affecting the process costs. The membrane area calculated in this research work is based on MTC based on lab-scale experimental results, and a detailed investigation of the MTC study needs to be caried out at different levels to observe the changes in MTC due to scale up. Finally, it is important to study the economic aspects of OMD process for its largescale implementation.

\section{Conclusions}

In this research work, the OMD process was studied through modeling and simulation to recover concentrated $\mathrm{Na}_{2} \mathrm{CO}_{3}$ from wastewater using an aqueous solution of $\mathrm{NaCl}$ as the osmotic solution. The model was validated with experimental results from the literature [25] and then was applied to study the effect of different parameters on water flux. For both cases (feed and osmotic solution concentration runs), simulation results were in good agreement with the experimental results with a maximum deviation of $7 \%$. The water transport flux was decreased by $50 \%$ when feed concentration was varied from 50 to $200 \mathrm{~g} \mathrm{~L}^{-1}$. On the other hand, the water transport flux was enhanced by $200 \%$, and the overall MTC was reduced by $40-50 \%$, when the osmotic solution concentration was increased from 100 to $300 \mathrm{~g} \mathrm{~L}^{-1}$. Likewise, the water transport flux was enhanced when the feed flow rate was increased from 1.2 to $3 \mathrm{~L} \mathrm{~h}^{-1}$ and the temperature was increased from 293 to $313 \mathrm{~K}$. Finally, the scaling up of the OMD for salt concentration was proposed, and the required area was estimated for industrial flow rates. OMD can be a viable process particularly for the conditions where effluents are discharged at high temperatures. However, few challenges like membrane fouling and osmotic solution recovery need to be addressed, and a full economic evaluation should be done before its large-scale implementation. Further, for crystallization of any salt using MD, long-term stability is a paramount issue, the crystallized salt needs to be removed before clogging up modules. Therefore, for continuous operation, a reservoir is required for the removal of salt.

\section{Abbreviations}

a: Activity (-); A: Area $\left(\mathrm{m}^{2}\right)$; : : Characteristic length (m); C: Concentration $\left(\mathrm{g} \mathrm{L}^{-1}\right)$; CPC: Concentration polarization coefficient (-); d: Diameter (m); D: Diffusion coefficient $\left(\mathrm{m}^{2} \mathrm{~s}^{-1}\right)$; $Q$ : Flow rate $\left(\mathrm{L} \mathrm{h}^{-1}\right)$; $h$ : Heat transfer coefficient (W $\left.\mathrm{m}^{-2} \mathrm{~K}^{-1}\right)$; $k$ : Mass transfer coefficient $\left(\mathrm{m} \mathrm{s}^{-1} \mathrm{~Pa}^{-1}\right) ; \mathrm{K}$ : Overall mass transfer coefficient $\left(\mathrm{m} \mathrm{s}^{-1} \mathrm{~Pa}^{-1}\right)$; v: Molar volume $\left(\mathrm{m}^{3} \mathrm{~mol}^{-1}\right)$; $x$ : Mole fraction (-); $M$ : Molecular weight $\left(\mathrm{kg} \mathrm{mol}^{-1}\right)$ : U: Overall heat transfer coefficient $\left(\mathrm{W} \mathrm{m}^{-2} \mathrm{~K}^{-1}\right) ; r$ : Pore radius (m); $P^{*}$ : Saturated vapor pressure (Pa); T: Temperature (K); $q^{*}$ : Total heat transfer $\left(\mathrm{W} \mathrm{m}^{-2}\right)$; $\mathrm{Q}$ : Flow rate $\left(\mathrm{L} \mathrm{h}^{-1}\right)$; $P$ : Vapor pressure $(\mathrm{Pa}) ; \mathrm{J}$ : Water flux $\left(\mathrm{L} \mathrm{m}^{-2} \mathrm{~h}^{-1}\right)$.

\section{Dimensionless numbers}

Re: Reynolds number; Sc: Schmidt number; Sh: Sherwood number; Nu: Nusselt number; Pr: Prandtl number.

\section{Greek letters}

$\varphi$ : Packing density; $v$ : Velocity $\left(\mathrm{ms}^{-1}\right) ; \mu$ : Viscosity (Pa s); $\rho$ : Density $\left(\mathrm{kg} \mathrm{m}^{-3}\right) ; \varphi_{B}$ : Solute-solvent interaction factor (-); $\tau$ : Tortuosity (-); $\in$ : Porosity (-); $\delta$ : Thickness (m)

\section{Subscript/superscript}

f: Feed; os: Osmotic solution; in: Inlet; sat: Saturation; out: Outlet; m: Membrane; $b$ : Bulk; $h$ : Hydraulic; $w$ : Water; $k$ : Knudsen diffusion.

\section{Acknowledgements}

Not applicable.

\section{Authors' contributions}

The work is a product of the intellectual environment of the whole team; and that all members have contributed in various degrees to the analytical methods used, to the research concept, and to the experiment design. All authors read and approved the final manuscript.

\section{Funding}

This research received no specific grant from any funding agency in the public, commercial, or not-for-profit sectors.

\section{Availability of data and materials}

The datasets generated and/or analyzed during the current study are available from the corresponding author on reasonable request.

\section{Declarations}

Ethics approval and consent to participate Not applicable.

\section{Consent for publication}

Not applicable.

\section{Competing interests}

The authors declare that they have no competing interests.

\section{Author details}

${ }^{1}$ Department of Chemical Engineering, University of Engineering and Technology, Peshawar, Pakistan. ${ }^{2}$ Department of Food Engineering, School of Food Engineering (FEA), State University of Campinas (UNICAMP), Campinas, Brazil. ${ }^{3}$ PCSIR Laboratories Complex, Jamrud Road, Peshawar 25120, Pakistan. ${ }^{4} \mathrm{~S}$ chool of Chemical and Materials Engineering, National University of Sciences and Technology, Islamabad, Pakistan. ${ }^{5}$ Faculty of Chemical and Materials Engineering, Shahrood University of Technology, Shahrood, Iran.

Received: 16 April 2021 Accepted: 27 June 2021

Published online: 07 July 2021 


\section{References}

1. Shrivastava P, Kumar R (2015) Soil salinity: A serious environmental issue and plant growth promoting bacteria as one of the tools for its alleviation. Saudi J Biol Sci 22(2):123-131

2. Kim DH (2011) A review of desalting process techniques and economic analysis of the recovery of salts from retentates. Desalination 270(1):1-8

3. Hao Y et al (2020) An ultrahighly permeable-selective nanofiltration membrane mediated by an in situ formed interlayer. J Mater Chem A 8(10):5275-5283

4. Ali W et al (2015) Reverse osmosis as one-step wastewater treatment: a case study on groundwater pollution Polish. J Chem Technol 17(4):42-48

5. Moraes BS et al (2014) Anaerobic digestion of vinasse from sugarcane biorefineries in Brazil from energy, environmental, and economic perspectives: Profit or expense? Appl Energy 113:825-835

6. Creusen $\mathrm{R}$ et al (2013) Integrated membrane distillation-crystallization: Process design and cost estimations for seawater treatment and fluxes of single salt solutions. Desalination 323:8-16

7. Ji X et al (2010) Membrane distillation-crystallization of seawater reverse osmosis brines. Sep Purif Technol 71(1):76-82

8. Rehman WU et al (2020) Electrospun hierarchical fibrous composite membrane for pomegranate juice concentration using osmotic membrane distillation. J Environ Chem Eng 8(6):104475

9. Rehman WU et al (2019) Pomegranate juice concentration using osmotic distillation with membrane contactor. Sep Purif Technol 224:481-489

10. Muhammad A, Younas M, Rezakazemi M (2017) Quasi-dynamic modeling of dispersion-free extraction of aroma compounds using hollow fiber membrane contactor. Chem Eng Res Des 127:52-61

11. Rehman WU et al (2017) Osmotic distillation and quality evaluation of sucrose, apple and orange juices in hollow fiber membrane contactor. J Chem Indus Chem Eng Q 23(2):217-227

12. Gabelman A, Hwang S-T (1999) Hollow fiber membrane contactors. J Membr Sci 159(1-2):61-106

13. Ahmad S et al (2020) Mass transfer modelling of hollow fiber membrane contactor for apple juice concentration using osmotic membrane distillation. Sep Purif Technol 250:117209

14. Brito Martínez M et al (2014) Membrane crystallization for the recovery of a pharmaceutical compound from waste streams. Chem Eng Res Des 92(2):264-272

15. Yoo M, Han S-J, Wee J-H (2013) Carbon dioxide capture capacity of sodium hydroxide aqueous solution. J Environ Manage 114:512-519

16. Sparenberg MC, Ruiz Salmón I, Luis P (2020) Economic evaluation of salt recovery from wastewater via membrane distillation-crystallization. Sep Purif Technol 235:116075

17. Das P, Dutta S, Singh KK (2021) Insights into membrane crystallization: a sustainable tool for value added product recovery from effluent streams. Sep Purif Technol 257:117666

18. Esfandiari A et al (2019) Computational fluid dynamic modeling of water desalination using low-energy continuous direct contact membrane distillation process. Appl Therm Eng 163:114391

19. Olatunji SO, Camacho LM (2018) Heat and mass transport in modeling membrane distillation configurations: a review. Front Energy Res 6:130

20. Ahmad $S$ et al (2021) Enzymatic monolithic reactors for micropollutants degradation. Catal Today 362:62-71

21. Khalifa A et al (2017) Experimental and theoretical investigations on water desalination using direct contact membrane distillation. Desalination 404:22-34

22. Ni W et al (2020) Simulation study on direct contact membrane distillation modules for high-concentration $\mathrm{NaCl}$ solution. Membranes 10(8):179

23. Lou J et al (2019) Computational fluid dynamics simulations of polarization phenomena in direct contact membrane distillation. J Membr Sci 591:117150
24. Salmón IR et al (2018) Salt recovery from wastewater using membrane distillation-crystallization. Cryst Growth Des 18(12):7275-7285

25. Ruiz Salmón I, Janssens R, Luis P (2017) Mass and heat transfer study in osmotic membrane distillation-crystallization for $\mathrm{CO} 2$ valorization as sodium carbonate. Sep Purif Technol 176:173-183

26. Younas M, Druon-Bocquet S, Sanchez J (2011) Experimental and theoretical mass transfer transient analysis of copper extraction using hollow fiber membrane contactors. J Membr Sci 382(1):70-81

27. Younas M, Druon-Bocquet S, Sanchez J (2010) Kinetic and dynamic study of liquid-liquid extraction of copper in a HFMC: experimentation, modeling, and simulation. AIChE J. 56(6):1469-1480

28. Al-Anezi AA-H et al Experimental investigation of heat and mass transfer in tubular membrane distillation module for desalination. 2012. 2012

29. Miyabe K, Isogai R (2011) Estimation of molecular diffusivity in liquid phase systems by the Wilke-Chang equation. J Chromatogr A 1218(38):6639-6645

30. Shaffer DL et al (2015) Forward osmosis: Where are we now? Desalination 356:271-284

31. Ibrahim G et al (2011) Effect of clouding agents on the quality of apple juice during storage. Food Hydrocolloids 25(1):91-97

32. Singh D, Sirkar KK (2012) Desalination of brine and produced water by direct contact membrane distillation at high temperatures and pressures. J Membr Sci 389:380-388

33. Zhang Z et al (2020) The role of osmotic agent in water flux enhancement during osmotic membrane distillation (OMD) for treatment of highly saline brines. Desalination 481:114353

34. Ravindra Babu B, Rastogi NK, Raghavarao KSMS (2008) Concentration and temperature polarization effects during osmotic membrane distillation. J Membr Sci 322(1):146-153

35. Miranda JM, Campos JBLM (2002) Mass transfer in the vicinity of a separation membrane-the applicability of the stagnant film theory. J Membr Sci 202(1):137-150

36. Lokare OR, Vidic RD (2019) Impact of operating conditions on measured and predicted concentration polarization in membrane distillation. Environ Sci Technol 53(20):11869-11876

37. Schofield RW, Fane AG, Fell CJD (1987) Heat and mass transfer in membrane distillation. J Membr Sci 33(3):299-313

38. Hitsov I et al (2015) Modelling approaches in membrane distillation: a critical review. Sep Purif Technol 142:48-64

39. Gonçalves FA, Kestin J (1981) The viscosity of $\mathrm{Na} 2 \mathrm{CO} 3$ and $\mathrm{K} 2 \mathrm{CO} 3$ aqueous solutions in the range $20-60^{\circ} \mathrm{C}$. Int J Thermophys 2(4):315-322

40. Simion Al et al (2015) Mathematical modelling of density and viscosity of nacl aqueous solutions. J Agroaliment Process Technol 21(1):41-52

41. Sandler SI (2017) Chemical, biochemical, and engineering thermodynamics. John Wiley \& Sons, Hoboken

42. Luis P, Van Aubel D, Van der Bruggen B (2013) Technical viability and exergy analysis of membrane crystallization: closing the loop of $\mathrm{CO} 2$ sequestration. Int J Greenhouse Gas Control 12:450-459

43. Drioli E et al (2006) Integrating membrane contactors technology and pressure-driven membrane operations for seawater desalination: energy, exergy and costs analysis. Chem Eng Res Des 84(3):209-220

44. Edwie F, Chung T-S (2013) Development of simultaneous membrane distillation-crystallization (SMDC) technology for treatment of saturated brine. Chem Eng Sci 98:160-172

45. Bouchrit R et al (2017) Membrane crystallization for mineral recovery from saline solution: Study case Na2SO4 crystals. Desalination 412:1-12

46. Tijing LD et al (2015) Fouling and its control in membrane distillationa review. J Membr Sci 475:215-244

47. Warsinger DM et al (2015) Scaling and fouling in membrane distillation for desalination applications: a review. Desalination 356:294-313

48. Tun CM et al (2005) Membrane distillation crystallization of concentrated salts_flux and crystal formation. J Membr Sci 257(1):144-155 
49. Agnaou M, Lasseux D, Ahmadi A (2016) From steady to unsteady laminar flow in model porous structures: an investigation of the first Hopf bifurcation. Comput Fluids 136:67-82

50. Xu J et al (2016) Effect of operating parameters and membrane characteristics on air gap membrane distillation performance for the treatment of highly saline water. J Membr Sci 512:73-82

51. Li W, Van der Bruggen B, Luis P (2014) Integration of reverse osmosis and membrane crystallization for sodium sulphate recovery. Chem Eng Process 85:57-68
52. Tun CM, Groth AM (2011) Sustainable integrated membrane contactor process for water reclamation, sodium sulfate salt and energy recovery from industrial effluent. Desalination 283:187-192

\section{Publisher's Note}

Springer Nature remains neutral with regard to jurisdictional claims in published maps and institutional affiliations.
Submit your manuscript to a SpringerOpen ${ }^{\circ}$ journal and benefit from:

- Convenient online submission

- Rigorous peer review

- Open access: articles freely available online

- High visibility within the field

Retaining the copyright to your article

Submit your next manuscript at $\boldsymbol{\nabla}$ springeropen.com 